\title{
Satellite observations of cloud regime development: the role of aerosol processes
}

\author{
E. Gryspeerdt, P. Stier, and D. G. Partridge \\ Department of Physics, University of Oxford, UK \\ Correspondence to: E. Gryspeerdt (gryspeerdt@atm.ox.ac.uk) \\ Received: 4 July 2013 - Published in Atmos. Chem. Phys. Discuss.: 30 August 2013 \\ Revised: 5 December 2013 - Accepted: 15 December 2013 - Published: 3 February 2014
}

\begin{abstract}
Many different interactions between aerosols and clouds have been postulated, based on correlations between satellite retrieved aerosol and cloud properties. Previous studies highlighted the importance of meteorological covariations to the observed correlations.

In this work, we make use of multiple temporally-spaced satellite retrievals to observe the development of cloud regimes. The observation of cloud regime development allows us to account for the influences of cloud fraction (CF) and meteorological factors on the aerosol retrieval. By accounting for the aerosol index (AI)-CF relationship, we reduce the influence of meteorological correlations compared to "snapshot" studies, finding that simple correlations overestimate any aerosol effect on CF by at least a factor of two.

We find an increased occurrence of transitions into the stratocumulus regime over ocean with increases in MODIS AI, consistent with the hypothesis that aerosols increase stratocumulus persistence. We also observe an increase in transitions into the deep convective regime over land, consistent with the aerosol invigoration hypothesis. We find changes in the transitions from the shallow cumulus regime in different aerosol environments. The strength of these changes is strongly dependent on Low Troposphere Static Stability and $10 \mathrm{~m}$ windspeed, but less so on other meteorological factors.

Whilst we have reduced the error due to meteorological and CF effects on the aerosol retrieval, meteorological covariation with the cloud and aerosol properties is harder to remove, so these results likely represent an upper bound on the effect of aerosols on cloud development and CF.
\end{abstract}

\section{Introduction}

Affecting both radiation and cloud processes, atmospheric aerosols have been recognised to have an important effect on the Earth's climate. The magnitude and sign of these effects constitute some of the largest uncertainties in attempts to model anthropogenic climate change (Forster et al., 2007). The aerosols themselves can scatter radiation directly back into space, but depending on their type, they can also absorb radiation, heating the atmosphere (e.g. Haywood and Shine, 1995). This heating of the atmosphere can stabilise the atmospheric column, which may lead to a reduction or an increase in cloud formation depending on the meteorological conditions (Koch and Del Genio, 2010).

Aerosols also act as cloud condensation nuclei (CCN), giving them an important role in cloud formation. Increasing the number of aerosols can result in the modification of the droplet size distribution, increasing the number of cloud droplets and decreasing the droplet radius. This decrease in effective radius results in an increase in the optical thickness of the cloud (assuming constant liquid water path) (Twomey, 1974). The resulting decrease in droplet size could also result in the suppression of precipitation, as the droplets take longer to reach precipitation forming sizes. This decrease in precipitation reduces the depletion of cloud water and may increase cloud lifetime (Albrecht, 1989). A strong correlation between aerosol optical depth (AOD) and cloud fraction $(\mathrm{CF})$ in the atmosphere has been observed (Kaufman et al., 2005). It has been suggested that aerosols influence the transition between open and closed celled stratocumulus (Rosenfeld et al., 2006), which may also result in a relationship between AOD and CF. In addition to an AOD-CF relationship, convective clouds also show a strong relationship between 
AOD and cloud top pressure (CTP), with the cloud height increasing in high AOD regions (Koren et al., 2005), possibly due to the modified droplet size distribution and ice processes (Rosenfeld et al., 2008; Stevens and Feingold, 2009). The increased cloud height may also lead to an increased cloud fraction at higher altitudes, with increases in convective anvil area being reported with increased AOD (Koren et al., 2010b).

However, these observed aerosol cloud correlations may not be due to aerosol effects on clouds, the correlation of aerosol and cloud properties could be the result of other factors such as large scale meteorology. Previous modelling studies suggest that the majority of the AOD-CF correlation can be explained by aerosol humidification increasing the AOD in regions of high relative humidity (Quaas et al., 2010). Similar results have been shown using satellite data (Engstrom and Ekman, 2010). Koren et al. (2010a) also find a dependence on relative humidity in the AOD-CTP relationship, but concluded that the observed relationship was not due to meteorological factors and was still consistent with an aerosol effect.

There is also the possibility that the observed AOD-CF correlation may be due to satellite retrieval errors, especially in regions of broken cloud. The scattering of light at the edges of clouds can result in a high bias of AOD retrievals in the vicinity of clouds (Wen et al., 2007), an effect which might be larger in regions of high CF. Spurious correlations may be generated by mis-identification of pixels as cloudfree, when they contain thin or sub-pixel cloud, known as "cloud contamination" (Kaufman et al., 2005). This contamination effect may be more common in regions with a large cloud fraction, resulting in a strong AOD-CF relationship. Some estimates of cloud contamination suggest that this cloud contamination effect could result in a $10-20 \%$ overestimation of the monthly mean AOD from the Moderate Resolution Imaging Spectrometer (MODIS) instrument (Zhang et al., 2005).

The majority of previous satellite studies of aerosol-cloud interactions are limited to a single overpass time and so have to infer important elements of the cloud lifecycle, such as convective development and stratocumulus breakup. Some previous studies have investigated the development of clouds in different aerosol environments using sub-daily time-resolved satellite datasets. Matsui et al. (2006) used the Visible and Infrared Scanner (VIRS) instrument on the Tropical Rainfall Measurement Mission (TRMM) to investigate the diurnal cycle of low clouds and MODIS to provide an aerosol retrieval. However, they restrict their study to low clouds, and do not account for the varying development of different cloud regimes, so may miss important effects. Lagrangian studies of marine boundary layer (MBL) clouds have also shown possible aerosol effects on cloud development. Mauger and Norris (2007) suggest that whilst there may be an aerosol effect, retrieval errors and meteorological covariations mean that a simple correlation may be overes- timating the cloud-fraction effect by $30 \%$. They were able to study the evolution of MBL clouds over several days, using MODIS to provide the cloud and aerosol products. However, there may be important effects happening on a sub-daily timescale, such as the strong diurnal cycle of convection, that are missed by this approach. Meskhidze et al. (2009) attempted to reduce retrieval errors by examining the evolution of cloud properties between the Terra and Aqua MODIS overpasses as a function Terra MODIS AOD. They found an apparent increase in the breakup rate of stratocumulus clouds in high AOD environments, but they did not account for meteorological covariation or the strong AOD-CF relationship, which may be generating spurious correlations.

Many previous approaches have focused on a specific cloud type, but the use of a wide CF or CTP range could result in meteorological covariation generating an apparent aerosol cloud relationship. The use of "snapshot" correlations, where both the aerosol and cloud properties are retrieved at the same time, also limits the ability to distinguish real aerosol-cloud interactions from meteorological covariation or retrieval errors.

This study addresses these issues using a regime based approach, building on Gryspeerdt and Stier (2012). We investigate how both the frequency of occurrence of cloud regimes and the probability of transitions between the regimes depends on satellite retrieved AI. We place particular emphasis on the development of $\mathrm{CF}$, due to the strong AOD-CF correlation making studies of aerosol effects on CF difficult. By studying transitions we aim to reduce spurious correlations due to meteorological covariation and retrieval errors. We also show how these studies of short term cloud development can be related to "snapshot" studies, where the aerosol and cloud properties are retrieved at the same time.

\section{Methods}

We split our clouds into regimes using the same method as Gryspeerdt and Stier (2012), which is based on a method used to determine cloud regimes for the International Satellite Cloud Climatology Project (ISCCP) (Rossow et al., 2005; Williams and Webb, 2009) but using data from the MODIS instrument. This method uses k-means clustering (Anderberg, 1973) on Cloud-Top-Pressure - CloudOptical-Depth histograms to objectively determine the cloud regimes. We then assign each $1^{\circ}$ by $1^{\circ}$ gridbox to a cloud regime using the gridbox mean $\mathrm{CF}$, cloud optical depth and cloud top pressure. Here we use the same regime centroids as Gryspeerdt and Stier (2012), shown in Table 1. The dominant physical cloud type represented by each of these regimes is not always clear, the thick mid-level is a mid-level convective type, the transition regime is a cloud type between the shallow cumulus and stratocumulus regimes. Figure 2 shows the frequencies of occurrence of the different regimes in the tropics $\left(30^{\circ} \mathrm{N}-30^{\circ} \mathrm{S}, 150^{\circ} \mathrm{W}-150^{\circ} \mathrm{E}\right)$. 
Table 1. Cloud regimes used in this study, from Gryspeerdt and Stier (2012). The mean rain rate is an annual mean over the tropics $\left(30^{\circ} \mathrm{N}-30^{\circ} \mathrm{S}\right)$ from the Global Precipitation Climatology Project (GPCP) $1^{\circ}$ product (Huffman et al., 2009).

\begin{tabular}{lrrrr}
\hline Regime & $\begin{array}{r}\text { Albedo } \\
(\%)\end{array}$ & $\begin{array}{r}\text { CTP } \\
(\mathrm{hPa})\end{array}$ & $\begin{array}{r}\mathrm{CF} \\
(\%)\end{array}$ & $\begin{array}{r}\text { Rain } \\
\left(\mathrm{mm} \mathrm{d}^{-1}\right)\end{array}$ \\
\hline Shallow Cumulus & 45.2 & 551 & 24.7 & 1.13 \\
Thick Mid Level & 62.8 & 261 & 97.6 & 10.56 \\
Thin Mid Level & 40.0 & 270 & 84.3 & 5.54 \\
Transition & 40.5 & 856 & 58.3 & 0.99 \\
Anvil Cirrus & 33.7 & 137 & 88.0 & 6.54 \\
Deep Convective & 69.7 & 127 & 98.6 & 23.68 \\
Stratocumulus & 48.7 & 745 & 83.9 & 1.75 \\
\hline
\end{tabular}

We use the two separate MODIS instruments to investigate links between aerosol properties and the properties of the cloud regimes. The MODIS instrument is flown on the Terra and Aqua, satellites in sun-synchronous orbits with equatorial crossing times of 1030 and 1330 LST respectively. The overpass time can vary slightly due to the wide swath of MODIS such that the time between overpasses can vary from between one and a half and four and a half hours. These instruments are of the same design, minimising error due to instrument differences. However, there are some slight differences between the instruments, with Terra MODIS suffering from more significant optical sensor degradation than Aqua (Levy et al., 2010; Xiong et al., 2008).

We use the MODIS L3 collection 5.1 data at $1^{\circ}$ by $1^{\circ}$ resolution for our cloud properties (Platnick et al., 2003) over the period 2003-2011 inclusive. We only use products from retrievals performed during daylight hours, ensuring that the retrieval time within the study region is known. We restrict the region studied to $150^{\circ} \mathrm{W}-150^{\circ} \mathrm{E}$, avoiding the region around the international dateline where the overpass order of the satellites relative to UTC can be unclear.

Whilst there are different possible MODIS CF products available, in this work we use the MODIS cloud optical properties "CF Combined" to determine the cloud regime. This CF product is determined by the cloud optical properties retrieval, which ignores pixels not surrounded by cloudy pixels and pixels where the retrieval algorithm fails. This gives a lower CF than the Cloud Mask CF (hereafter referred to as CF Day), but it is directly related to the cloud optical properties retrieval and the ISCCP style CTP-optical depth histogram produced by MODIS previously used for regime determination. It also reduces the probability of having heavy aerosol classified as cloud (Hubanks et al., 2008).

For atmospheric relative humidity at $850 \mathrm{hPa}, 10 \mathrm{~m}$ wind speed, $500 \mathrm{hPa}$ vertical velocity $\left(\omega_{500}\right)$ and low troposphere static stability (LTSS - calculated from the temperature profile, Klein and Hartmann, 1993), we use data from the full resolution ECMWF ERA-Interim dataset re-gridded to a $1^{\circ}$ by $1^{\circ}$ grid (Dee et al., 2011). The meteorological properties are re-sampled to 10:30 LST by taking a weighted average of the properties at the two closest times provided by ERAInterim.

The aerosol data we use here are the level 3 daily aerosol data from MODIS collection 5.1 (Remer et al., 2005). We use the AOD QA_mean and angstrom exponent QA_mean products to generate the aerosol index (AI). The Angstrom exponent provides a size dependent measurement and so the AI, as AOD multiplied by Angstrom exponent, is thought to provide a better estimate of CCN than the AOD (Nakajima et al., 2001).

To ensure that we remove correlations caused by seasonal variations or climatological spatial gradients in cloud and aerosol properties (Grandey and Stier, 2010), we define high and low aerosol as the highest and lowest quartile for each $1^{\circ}$ by $1^{\circ}$ location, regime and season separately. This means that the difference between high and low AI varies by location and regime.

We also use the ECMWF Monitoring Atmospheric Composition and Climate (MACC) AOD product as an AOD dataset to investigate the possibility of sampling errors (Sayer et al., 2010b) caused by the lack of AOD retrievals in high CF regimes. The MACC product uses assimilated MODIS data, so while it cannot account for cloud contamination or relative humidity issues, it does provide AOD estimates for cloud covered regions. The performance of MACC Angström exponent has not been evaluated, so we do not create a MACC AI product. Whilst this limits value of a direct comparison between MODIS AI and MACC AOD, we feel the benefits of using MODIS AI outweigh these drawbacks. Throughout this work, the low AI population is the lowest AI quartile and the high AI population is the highest AI quartile.

\subsection{Transitions}

The frequency of occurrence of the regimes is determined in part by the CF, so the strong AI-CF correlation would be likely to cause change in the frequency of occurrence of the regimes with increasing AI. Changes in the mean properties of the regimes, such as precipitation rate, are less likely to be influenced by strong AI-CF correlation, as they do not depend on the frequency of occurrence of the regimes (and hence regime $\mathrm{CF}$ ). Such properties include effective radius and cloud droplet number concentration as well as the probability of transitions between regimes.

The dual overpasses of the MODIS instruments allows us to look at the transitions between cloud types over the period between roughly 10:30-13:30 LST. We refer to this period as the timestep throughout this work. To minimise sources of variance, we restrict our study to the tropics $\left(30^{\circ} \mathrm{N}-30^{\circ} \mathrm{S}\right)$ where the strong diurnal cycle is the main driver of variability, rather that the synoptic systems of the mid-latitudes. Over ocean in the tropics, the diurnal cycle accounts for approximately $20 \%$ of the variability in brightness temperature. Over land the percentage variability explained by the 

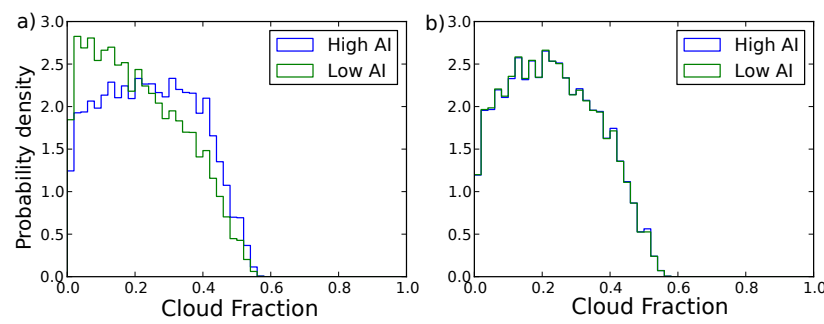

Fig. 1. The shallow cumulus regime cloud fraction $(\mathrm{CF})$ distribution for low and high AI populations. Before accounting for $\mathrm{CF}$ variations (a), there is a strong link between $\mathrm{AI}$ and $\mathrm{CF}$, afterwards (b), this link is reduced. We also correct for $500 \mathrm{hPa}$ vertical velocity, low troposphere static stability, $850 \mathrm{hPa}$ relative humidity and $10 \mathrm{~m}$ windspeed. This step is performed for each regime, separately over land and ocean.

diurnal cycle is larger, at $30-40 \%$, representing a significant contribution to the total variability (Yang and Slingo, 2001).

Regime transitions (not to be confused with the transition regime - see Table 1) are only defined when there is a valid retrieval and regime assignment at the start and the end of the timestep in the same location. Note that if there is no change in the regime type over the timestep, we consider this a transition between regimes of the same type. At a resolution of $1^{\circ}$ by $1^{\circ}$, the scale of a single gridbox in the tropics is roughly $120 \mathrm{~km}$, so over $3 \mathrm{~h}$ we are on the limit of whether advection should be considered. Throughout this work we neglect the effects of advection as the cloud regimes are often similar over a larger size than $1^{\circ}$ by $1^{\circ}$. We investigate the validity of this assumption in this work.

We determine statistical significance for the changes in the transition histograms using a bootstrap method (Efron, 1979). We consider a change in transition frequency as significant if the $95 \%$ confidence intervals of the transition frequency for the high AI and low AI populations do not intersect.

\subsection{Meteorological effects}

Meteorological effects exert a strong influence on both cloud development and AI and so must be accounted for in any study into aerosol-cloud interactions (Koren et al., 2010a). Even in the absence of other meteorological influences, the diurnal cycle results in transitions between cloud regimes. For example, the increase in convection over land during the day will result in transitions into the deep convective regime, and the breakup of stratocumulus clouds over the ocean during the day will result in transitions out of the stratocumulus regime, into the transition and shallow cumulus regime. We aim to determine whether separating our data into high and low AI populations modifies the regime transition probabilities.

Given the strong link between $\mathrm{CF}$ and $\mathrm{AI}$ it is necessary to account for possible effects linking $\mathrm{CF}$ and $\mathrm{AI}$ at the start of the timestep. This process is illustrated in Fig. 1. Normalised histograms of CF are made for the high and low AI populations. For each histogram bin, data-points are drawn at random from the population with the larger frequency density in that bin until both distributions match. This is performed independently for each bin and the entire process is repeated until the populations have sufficiently similar normalised histograms. Investigations suggest that this process reduces the difference in the mean CF of the high and low AI populations to below $0.1 \%$ at the start of the timestep for each of the regimes. This process is performed for each regime over land and ocean separately. It is not used when determining the frequency of occurrence of the regimes, only when investigating the frequency of the transitions between the regimes. While this process removes any effects of aerosol on CF, previous studies have shown that this represents a small fraction of the overall AI-CF correlation (Quaas et al., 2010). The main result of this process is to remove non-aerosol effects linking $\mathrm{CF}$ and $\mathrm{AI}$.

Figure 1 also demonstrates how the diurnal cycle may result in apparent aerosol effects on the transition frequencies if this correction is not performed. If we consider a system made up of two regimes, defined only by high or low CF, clouds starting in the low $\mathrm{CF}$ regime will transition to the high $\mathrm{CF}$ regime if their $\mathrm{CF}$ is increased. As demonstrated in Fig. 1, the high and low AI populations have different $\mathrm{CF}$ distributions. If this were an example of the low $\mathrm{CF}$ regime, an increase in CF of all the clouds would generate more transitions for the high AI population, as it has more higher CF data-points, despite all the included data-points being part of the shallow cumulus regime. After the correction process, this effect no longer occurs, as both populations have the same CF distribution, so there would be no difference in the frequency of transitions between the high and low AI populations.

As the AI-CF relationship may also be influenced by relative humidity (Quaas et al., 2010), we perform this step with ERA-Interim $850 \mathrm{hPa}$ relative humidity. We also use this technique to ensure the high and low AI populations have the same distributions of divergence (which can be approximated by $500 \mathrm{hPa}$ vertical velocity), $10 \mathrm{~m}$ windspeed (Engstrom and Ekman, 2010) and LTSS (Mauger and Norris, 2010), as they have all been suggested to affect the AI-CF relationship.

Other meteorological properties, such as Sea Surface Temperature have been shown to have important influences on cloud evolution (Pincus et al., 1997), but they are thought to have less of an influence on the apparent strength of aerosolcloud interactions. Whilst we do not account for variation in all meteorological parameters, the ones considered have previously been shown to have strong correlations with aerosol and cloud properties (Koren et al., 2010a). By ensuring the high and low AI populations have the same distribution of each of these meteorological variables within each regime, we reduce meteorological covariations controlled by these variables. 

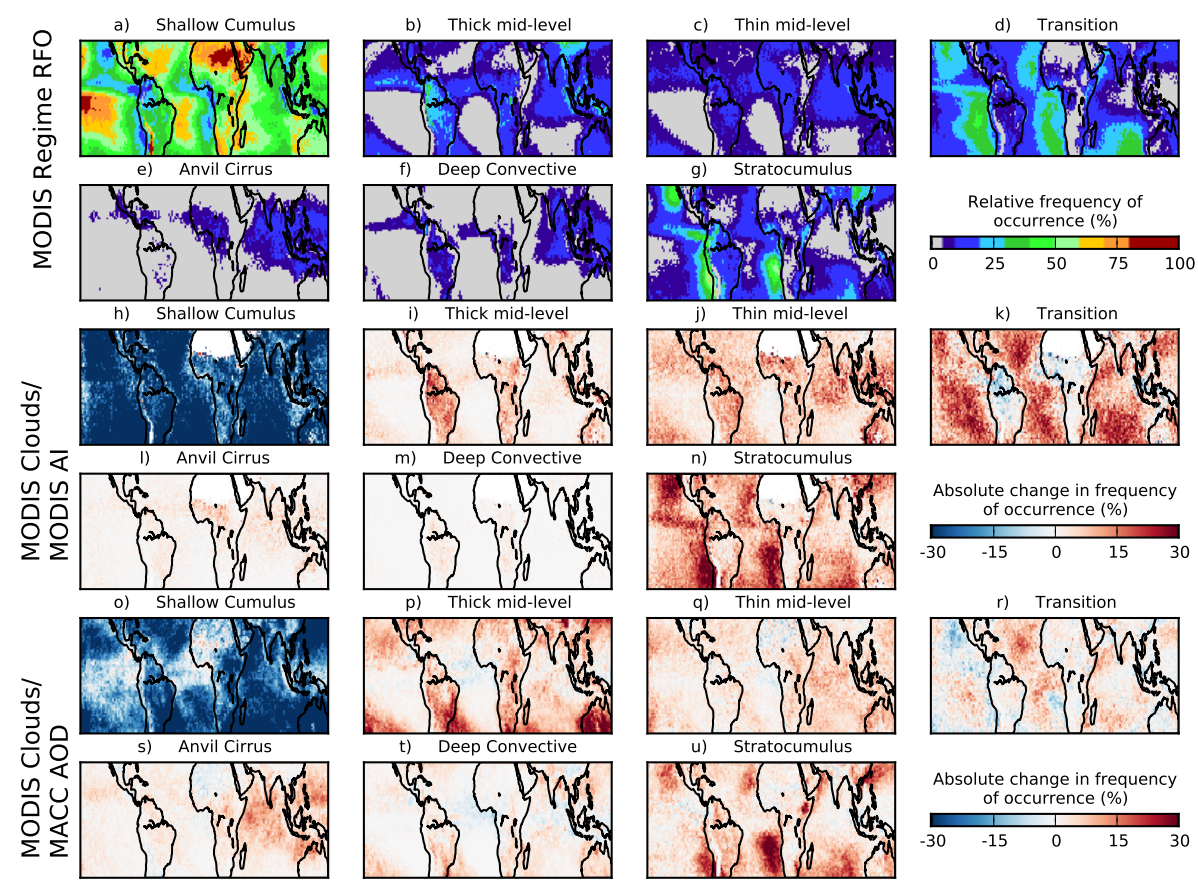

Fig. 2. (a-g) Relative frequency of occurrence (RFO) of each of the MODIS cloud regimes from Terra MODIS (2003-2011). The RFO is defined such that the sum of the RFOs for all of the regimes is $100 \%$. (h-n) The difference in frequency of occurrence of the regimes between the lowest and the highest MODIS AI quartiles. (o-t) as (h-n) but using MACC AOD instead of MODIS AI as the aerosol product. Note that the effect of $\mathrm{CF}$ on the AI retrieval is not accounted for when determining changes in regime RFOs.

This process reduces the amount of data available for study by about half for all the regimes. At the start of the timestep there are approximately 500000 data-points in the shallow cumulus regime and 50000 in the deep convective regime, the most and least numerous regimes respectively. Requiring a coincident MODIS AI retrieval removes the transitions from the deep convective regime, as there are not enough co-located MODIS AI retrievals in this regime due to the high CF. Transitions from the deep convective regime are still present when using MACC AOD, as it provides values for AOD in completely cloud covered regions.

We remove the AI-CF relationship at the time of the Terra (morning) overpass. To investigate the possible effect of aerosol on $\mathrm{CF}$, we investigate the recovery of the AI-CF relationship over the $3 \mathrm{~h}$ timestep. We define $d(\mathrm{CF})$ (Eq. 1) as the difference between the mean change in $\mathrm{CF}$ of the low and high AI populations over the timestep. If the AI used is retrieved at the start of the timestep and the CF sampling is performed as described in this section, $d(\mathrm{CF})$ is the difference in mean CF between the high and low AI populations at the end of the timestep. This is extended to different variables, for example, $d$ (LWP) would be the difference in mean Liquid Water Path evolution between the high and low AI populations.

$d(\mathrm{CF})=\overline{\Delta \mathrm{CF}[\text { High } \mathrm{AI}]}-\overline{\Delta \mathrm{CF}[\text { Low } \mathrm{AI}]}$

\section{Results}

\subsection{Regime RFO changes}

Figure 2 shows the change in regime relative frequency of occurrence (RFO) between the lowest and the highest gridbox AI quartiles, the scale being the change in RFO. A positive change indicates a regime becoming more common at higher AI. There is a clear decrease in the shallow cumulus regime at high AI (Fig. 2h), almost universally across the globe, although the decrease is less pronounced around the Atlantic coast of Africa, in the Arabian Sea and over Indonesia. We see a corresponding increase in the stratiform cloud types, with the increase in stratocumulus regime (Fig. 2n) being more confined to the edge of continents than the transition regime, which increases over most of the globe (Fig. 2k). The decreases in the RFO of the transition regime appears to be due to thickening of the cloud in that area, seen as an increase in stratocumulus cloud. The increases in stratiform cloud are consistent an increase in AI being correlated with an increase in $\mathrm{CF}$ in the stratocumulus and transition regimes.

There is also an almost universal increase in the RFO of the mid-level regimes. A small increase in the Anvil Cirrus type is also observed, confined to regions where it already commonly occurs (Fig. 21). The increases in the convective types (anvil cirrus and thick mid-level) are consistent with the convective invigoration hypothesis of aerosol effects on 
convective clouds, resulting in an increased cloud top height. There is very little observed change in the Deep Convective regime RFO when using MODIS AI (Fig. 2m), most likely due to the low regime RFO and high cloud fraction restricting the number of locations where the Deep Convective regime exists with a valid AI retrieval.

Similar changes in regime frequency are observed when using the MACC AOD product, with increases in deep convective (Fig. 2t) and stratocumulus regimes (Fig. 2u). The decrease in the deep convective RFO in some regions when using MACC may be due to the effect of wet scavenging, which may not be sampled by the standard retrieval (Grandey et al., 2013). This may also be linked to the smaller increase in the anvil cirrus regime in the same region, which also have a very high mean CF. The decrease in shallow cumulus RFO with increasing MACC AOD (Fig. 2o) is slightly less pronounced than when using MODIS AI. This may also be due to the effect of wet scavenging, with a reduced change in shallow cumulus clouds being easiest to see over equatorial Atlantic and East Pacific where the anvil cirrus and deep convective regimes are more common. The increase in the stratocumulus regime is also less pronounced, although it does occur in the same geographic locations as when using MODIS AI.

\subsection{Transitions}

To investigate the frequencies of transitions between the regimes during the $3 \mathrm{~h}$ timestep, we make use of transition histograms similar to those of Lee et al. (2013). These are two dimensional histograms, normalised such that the sum of all the transition probabilities for any given starting regime is $100 \%$ (a regime has to transition into another type). For this reason, we also refer to situations where there is no change in regime over the timestep as a transition. As an example, the top-right bin in each of the transition histograms indicates the strength of the stratocumulus (Strat.) to shallow cumulus (S.C.) transition. If this was $100 \%$, all the stratocumulus regime clouds at the start of the timestep would end the timestep as the shallow cumulus regime.

The majority of the transitions between the regimes (Fig. 3a, b) occur between regimes of the same type (i.e. there is no change in the regime type over the timestep). The dominant off-diagonal elements of the transition histogram display the strong elements of the diurnal cycle. Over land (Fig. 3a) there are stronger transitions between the shallow cumulus, thick mid-level (Thick M.L.) and deep convective (D. Conv.) regimes. The shallow cumulus - thick mid-level - deep convective pathway is referred to as the convective pathway in this work.

Over ocean, the transitions from the transition regime to shallow cumulus regime stand out, as do transitions from the stratocumulus regime to transition regime (Fig. 3b). These are a result of the breakup of stratocumulus clouds during the day (Wood, 2012). The breakup of stratocumulus is not so obvious over land, where the stratocumulus regime can be

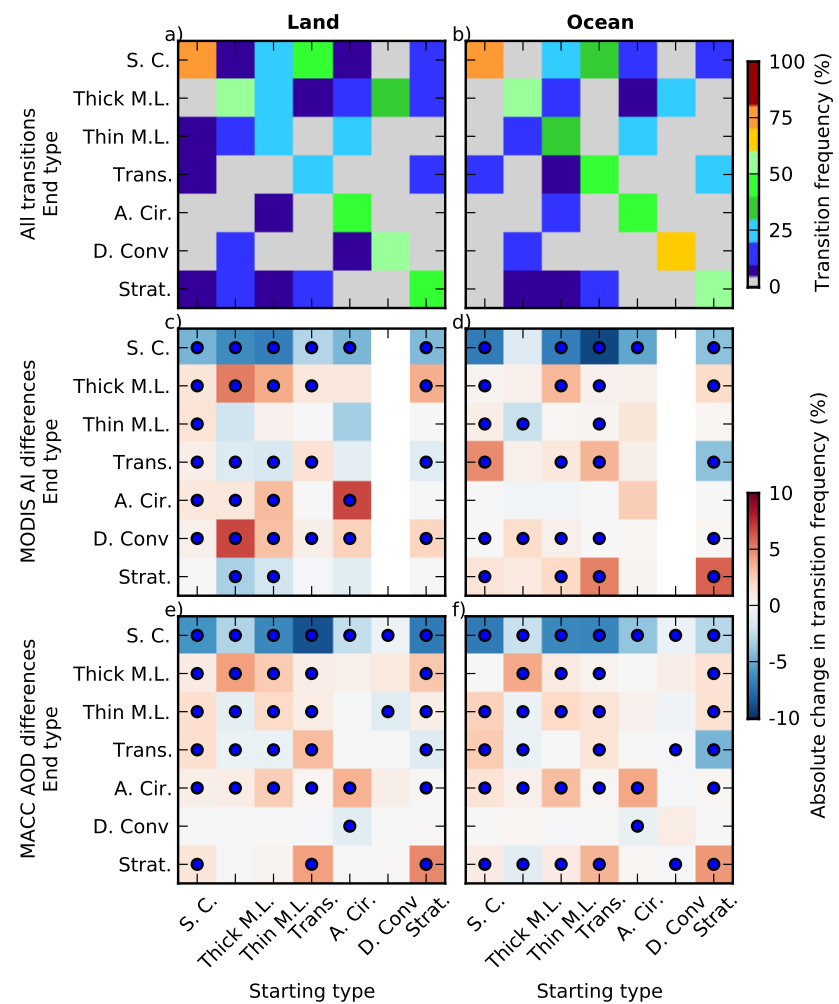

Fig. 3. Regime transition histogram showing the conditional probability of a given transitions between regimes over (a) land and (b) ocean during the $3 \mathrm{~h}$ period between 1030 and $1330 \mathrm{LST}$, given each starting regime. Each column sums to $100 \%$. The difference in the histograms between the highest and lowest MODIS AI quartile days over (c) land and (d) ocean, and using MACC AOD over (e) land and (f) ocean. Positive values indicate an increase in the frequency of the transition with increasing AI. Note the non-linear colourbar in (a) and (b). The dots indicate $95 \%$ statistical significance. This plot covers regime transitions for the tropical region $\left(30^{\circ} \mathrm{N}-30^{\circ} \mathrm{S}\right)$.

a precursor to convective cloud types, in contrast to its behaviour over ocean. This is shown by the higher probability of the stratocumulus to thick mid-level transitions over land compared to over ocean. In this work, we refer to the shallow cumulus-transition-stratocumulus pathway as the stratiform pathway (the stratiform regimes in order of increasing $\mathrm{CF}$ ).

When investigating the change in transition frequencies, we account for the strong AI-CF correlation using the method described in Sect. 2.2. The difference between the regime transition histograms for those transitions starting in the highest AI quartile and the lowest AI quartile (Fig. 3c, d) is less pronounced than the change in regime RFOs (Fig. 2b). This is partly because the transitions only consider the results of an effect over $3 \mathrm{~h}$ rather than the integrated effect considered by "snapshot" correlations. The differing diurnal cycle over land and ocean generates different features in the difference histograms over land and ocean. Due to the restricted number of deep convective regime clouds with a colocated MODIS AI retrieval, there are no observed changes 
in transitions from the deep convective regime (Fig. 3c, d) when using MODIS AI.

The transitions histograms over both land and ocean (Fig. 3c, d) show a distinct decrease in all of the transitions into the shallow cumulus regime with increasing AI. They also both show in increase in transitions out of the shallow cumulus regime, with the increase in transitions to the transition regime over ocean being more pronounced.

Over land (Fig. 3c) the dominant effect is the increase in transitions into the thick mid-level and deep convective regimes, suggesting that the convective pathway transitions occur more frequently in the high AI population. There are also increases in transitions to the Anvil Cirrus regime (A. Cir.). The particular transitions to note for the convective pathway are the increase in thick mid-level to deep convective and the increase in stratocumulus to thick mid-level transitions, as they are both important for the convective pathway over land.

These changes in convective pathway transition frequencies are consistent with the hypothesis of invigoration of convective clouds by aerosols. There are increases in transitions into the deep convective regime and the anvil cirrus regime, which are consistent with an invigoration hypothesis (Williams et al., 2002; Koren et al., 2005) and an increase in anvil area (Koren et al., 2010b). The increase in the stratocumulus to thick mid-level transition over land is also characteristic of an increase in convective activity with increasing AI. Convection over land in the tropics can develop from widespread low clouds with high CF (Machado et al., 2002), which appears here as the stratocumulus regime. The transitions from stratocumulus to thick mid-level represent the initiation of convection, while the thick mid-level to deep convective transition is a later state in the cloud lifecycle. The increase in thick mid-level to thick mid-level transitions is at the expense of transitions from thick mid-level to the shallow cumulus or stratocumulus regimes, and so can also be interpreted as a strengthening of convection with increasing AI.

We see very little increase in the convective pathway over ocean. This may be due to the smaller AI variance over ocean (smaller difference between high and low AI) and a lower frequency of occurrence of the deep convective regime over ocean (Fig. 5e). It is also possible that the diurnal cycle is playing a role. Over the ocean we expect convective systems to be dissipating through the day (Chen and Houze, 1997), compared to convective systems over land, where they would be intensifying.

There are also changes to transitions involving the stratiform cloud types. The stratocumulus regime becomes more persistent over ocean (Fig. 3d), with both increases in the occurrence of stratocumulus to stratocumulus transitions and in transitions into the stratocumulus regime. There are also increases in the transitions into the transition regime from the shallow cumulus regime, and decreases in the occurrence of stratocumulus-transition regime transitions.
Although we have observed an increase in stratocumulus persistence with increasing AI, previous studies have observed an increase in the rate of stratocumulus breakup. They show increased AOD is correlated with a larger decrease in CF between the Terra and Aqua MODIS overpass times (1030 and 1330 LST respectively). They speculate that this decrease may be due to increased evaporation of the cloud at the cloud top, caused by increased evaporation of the smaller cloud droplets that are more common in polluted regions (Meskhidze et al., 2009). These results are supported by some modelling studies, which show an increased rate of stratocumulus breakup in high aerosol environments (Sandu et al., 2008).

Our analysis has found the opposite effect (Fig. 3d), suggesting that stratocumulus breakup is suppressed in high AI regions. This is shown by the reduced probability of a stratocumulus to transition regime transition in higher AI environments, suggesting longer lived stratiform clouds and resulting in an increase in stratiform CF with increased AI. This slowing of the stratocumulus breakup may provide further evidence that aerosols might be influencing the transition from closed to open celled stratocumulus (Rosenfeld et al., 2006).

This difference is due to our more sophisticated accounting of meteorological properties, especially $\mathrm{CF}$, at the start of the timestep. In stratocumulus clouds, initial CF is correlated with the decrease in $\mathrm{CF}$ over the timestep, such that a high initial $\mathrm{CF}$ is correlated with a large $\mathrm{CF}$ decrease over the timestep. When coupled with the strong AI-CF relationship, this results in an apparent aerosol induced reduction in $\mathrm{CF}$ over the timestep. If the strong AI-CF relationship is accounted for, a slight increase in CF over the timestep with increasing AI is found, which exhibits itself in this study as an increase in stratocumulus persistence with increasing AI.

The use of MACC AOD to provide aerosol properties colocated with the MODIS cloud properties does suggest some possible sampling errors, although the main features of the transition histograms are the same. Whilst there is still an increase in the convective pathway transitions when using MACC AOD, there is no longer an increase in transitions into the deep convective regime (Fig. 3e). This difference is probably due to wet scavenging in cloud-covered scenes in the MACC product. These are under-sampled in the MODIS product, as aerosol properties can not be retrieved in cloud covered scenes. There is some uncertainty over whether the changes as a function of MODIS AI or MACC AOD are more reliable, as although MACC eliminates sampling issues, its accuracy in cloud covered scenes is not known (Grandey et al., 2013). There is also a strengthening of the stratiform pathway over land compared to MODIS AI. Over ocean (Fig. 3f), there is a very slight decrease in the strength of the stratiform pathway compared to MODIS, which may also be due to sampling issues in the high CF stratocumulus regime. 

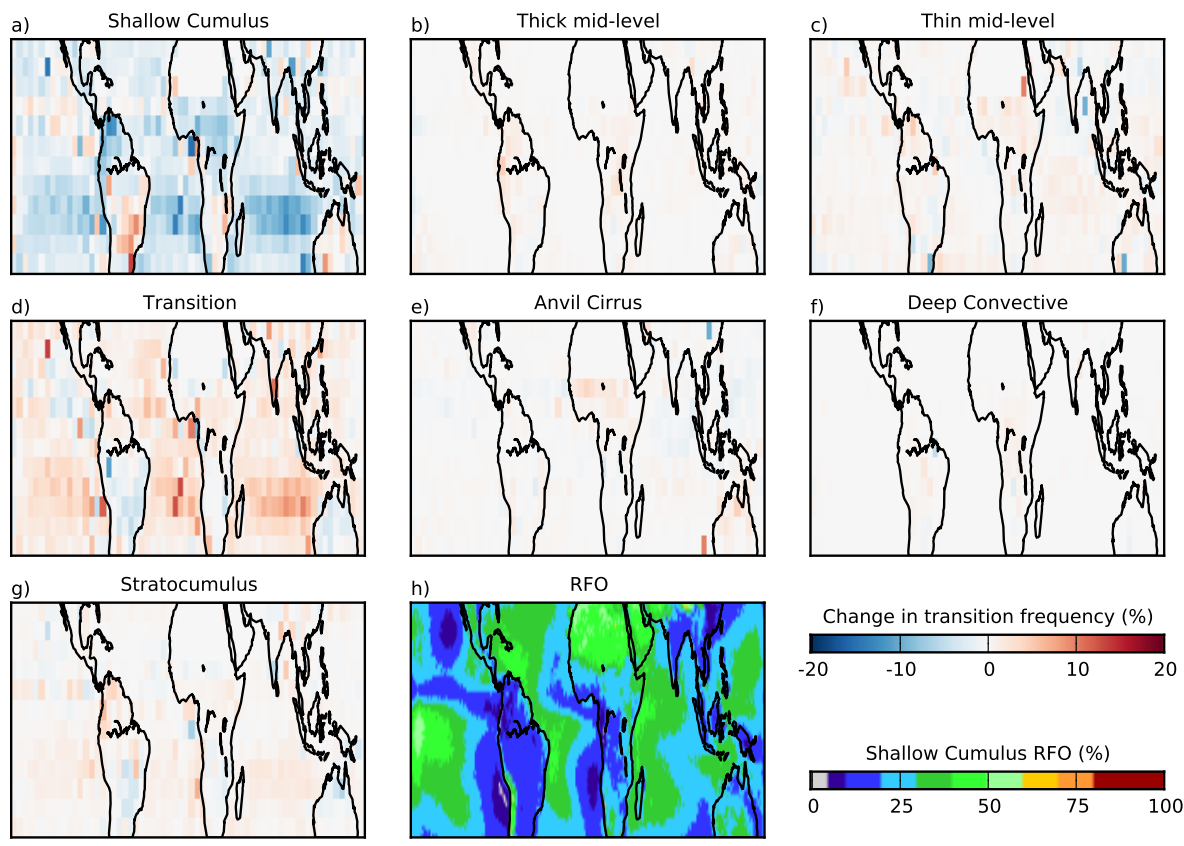

Fig. 4. Difference in transition frequency between the low and high AI populations for transitions from the shallow cumulus regime. These maps correspond to the first column of Fig. 3d. The relative frequency of occurrence of the shallow cumulus regime is shown in the final plot. These plots all use MODIS Aqua and Terra data from 2003-2011, between $30^{\circ} \mathrm{N}$ and $30^{\circ} \mathrm{S}$.

\subsection{Regional effects}

We concentrate on transitions from the shallow cumulus regime, as it has the largest frequency of occurrence across the tropics (Fig. 2a). To prevent regional variations in the AICF relationship from affecting the transition frequency spatial patterns, we apply the method described in Sect. 2.2 to regions of $5^{\circ}$ by $5^{\circ}$. This ensures that each location has the same CF distribution, rather than just each regime. This resolution gives enough data to determine the transition frequencies whilst still maintaining a reasonable spatial resolution and acceptable sampling errors (Grandey and Stier, 2010).

The changes in transition frequencies observed in Fig. 4 are well correlated with both increases in $d(\mathrm{CF})$ and decreases in $d(\mathrm{CTP})$ (Fig. 5a, $\mathrm{h}$ ). The increase in $d(\mathrm{CF})$ is much less pronounced in the Northern Hemisphere, although over land it is much larger, generating a corresponding larger decrease in the shallow cumulus to shallow cumulus transition (Fig. 4a). In this case, the decrease in CTP may be a consequence of the increase in CF, as MODIS is known to have difficulties in retrieving the CTP of broken low clouds (Zuidema et al., 2009).

The Liquid Water Path (LWP) for shallow cumulus clouds is larger in high AI environments than low AI environments across the tropical oceans, apart from the Atlantic (Fig. 5c, g). Over the timestep, $d$ (LWP) shows a pattern similar to but opposite in sign to that of $d(\mathrm{CF})$ (Fig. 5a). The increase in LWP at the start of the timestep is similar to model results, with most General Circulation Models (GCMs) pre- dicting a large increase in LWP with increasing AOD (Quaas et al., 2009). Our study finds a negative $d$ (LWP) in the shallow cumulus regime, suggesting that increased AI is correlated with a reduction in LWP. This decrease in observed mean LWP is not due to a decrease in LWP of existing clouds at high AI. It results from an increase in low LWP clouds, which generates an increase in $\mathrm{CF}$ in the high AI population. The CF weighted LWP increases over the timestep (not shown), suggesting that the total cloud water increases, while the mean in-cloud water decreases. LWP retrievals may not be reliable in high aerosol regions (Seethala and Horvath, 2010) and although we are looking at changes in LWP rather than absolute magnitudes, these changes may also be unreliable.

Given the strong relationship observed in $d(\mathrm{CF})$, we also consider the changes in the MODIS CF Day product. The CF Day product is created from the MODIS cloud mask (MOD35), rather than the cloud properties retrieval (MOD06, referred to as CF in this work). The cloud properties retrieval (MOD06, CF) requires each pixel where the retrieval is performed to be surrounded by cloudy pixels and so it has a smaller cloud fraction than the total cloud mask (MOD35, CF Day). The CF Day product may also include some heavy aerosol flagged as cloud (Hubanks et al., 2008), and for this reason is not used when assigning the regimes or when considering the effects of cloud on $\mathrm{AI}$ at the start of the timestep. The ratio between CF and CF Day can also be affected by the cloud shape, as it is dependent on the perimeterto-area ratio of the clouds as well as the amount of heavy 
aerosol. CF Day is often higher in the high AI population at the start of the timestep (Fig. 5b), especially in regions where the primary source of aerosol is dust, such as the West coast of Africa and the Arabian Sea. This suggests that the increased CF Day in these regions is due to aerosol contamination of the cloud retrieval, but it may also be due to a changing area to perimeter ratio. As CF Day is not the same for the high and low AI populations at the start of the timestep (Fig. 5b), the value of $d$ (CF Day) at the end of the timestep (Fig. 5f) may be affected by the difference in the initial state. We find $d$ (CF Day) shows a similar pattern to $d(\mathrm{CF})$, with increased $d$ (CF Day) in the Southern Hemisphere. The apparent decrease of $d$ (CF Day) in the Northern Hemisphere may be due to the difference in CF Day between the high and low AI populations at the start of the timestep.

\subsection{Meteorology}

If we consider $d(\mathrm{CF})$ of the shallow cumulus regime in a meteorological variable space instead of a latitude-longitude space, we can see the dependence of the correlations between aerosol and the CF development as a function of meteorological variables (Fig. 6).

As expected, the shallow cumulus regime tends to occur in regions of subsidence and low LTSS, although it is not exclusively confined to these locations (black lines in Fig. 6). We find that the $d(\mathrm{CF})$ at the end of the $3 \mathrm{~h}$ timestep is not a strong function of $\omega_{500}$. LTSS shows a much clearer relationship, with $d(\mathrm{CF})$ increasing with increasing LTSS. The increase in $d(\mathrm{CF})$ is particularly clear over the range from 12 to $20 \mathrm{~K}$, where $d(\mathrm{CF})$ increases linearly from around 0.02 to around 0.08 . Outside of this range the relationship becomes harder to determine due to the reduction in data volumes and correspondingly larger errors (blue lines in Fig. 6).

Shallow cumulus clouds develop differently under strong inversions, spreading out and tending to be topped by a stratiform layer (Stevens et al., 2001). This more stratiform character could lead to the increases in $d(\mathrm{CF})$ in higher LTSS regions. The increase in $d(\mathrm{CF})$ with increasing LTSS matches well with the observation of increased $d(\mathrm{CF})$ in high LTSS regions of the Southern Hemisphere (Fig. 5a) and may explain the hemispheric difference in $d(\mathrm{CF})$.

Across the majority of the range investigated for relative humidity, it appears to have a relatively poor relationship to $d(\mathrm{CF})$. There is perhaps an increase in $d(\mathrm{CF})$ with increasing relative humidity above around $70 \%$, but given the smaller quantity of data and larger uncertainty in this range, it is hard to make a conclusive determination.

Windspeed at $10 \mathrm{~m}$ appears to have a significant effect on $d(\mathrm{CF})$ above $8 \mathrm{~m} \mathrm{~s}^{-1}$, where we observe a large increase in $d(\mathrm{CF})$ from around 0.04 to over 0.1 . Below this range, there is a much less significant relationship between windspeed and $d(\mathrm{CF})$. The cause of the relationship between windspeed and $d(\mathrm{CF})$ is not clear. Sea spray is known to be related to windspeed (Woodcock, 1953), where wind and waves force air bubbles to burst. When the $10 \mathrm{~m}$ wind reaches a threshold of around 7-11 $\mathrm{m} \mathrm{s}^{-1}$,"spume" droplets are also formed, where droplets are separated from wave crests by the wind (e.g. Kientzler et al., 1954; Andreas, 1998). If this increase in sea salt aerosol increases the variance in AI, this may result in an increase of $d(\mathrm{CF})$. Another possible explanation is the effect of whitecaps increasing the aerosol retrieval (Sayer et al., 2010a), as significant whitecaps begin to occur above about $5 \mathrm{~m} \mathrm{~s}^{-1}$, although how this would increase $d(\mathrm{CF})$ unclear.

Whilst there is a small influence of initial CF on $d(\mathrm{CF})$ at very low values of $\mathrm{CF}$, in general there is a very weak relationship between them, with a slight increase in $d(\mathrm{CF})$ at higher initial CF (Fig. 6).

\subsection{Advection}

The geographical pattern of $d(\mathrm{CF})$ for the shallow cumulus regime (Fig. 5) and the link to LTSS (Fig. 6) suggests the possibility of advection having an important role. At the MODIS L3 resolution of $1^{\circ}$ by $1^{\circ}$, we are at the limit of whether advection should be considered over the $3 \mathrm{~h}$ timestep. Although we have neglected advection effects, within a $3 \mathrm{~h}$ timestep an airmass may well have left the $1^{\circ}$ by $1^{\circ}$ gridbox in which it started the timestep. The movement of airmasses between gridboxes could generate transitions between the regimes, reducing the apparent strength of any aerosol effect on the transitions. Large scale meteorology may generate systematic errors. The tropical subsidence regions have a strong East-West gradient in CF, with the trade winds transporting air parcels down gradient. This results in higher $\mathrm{CF}$ air being advected into a gridbox during the timestep, an effect which may be important if advection is neglected. Advection may be generating the positive $d(\mathrm{CF})$ in the shallow cumulus regime in the trade wind cumulus regimes, by advecting in stratocumulus clouds into a gridbox during the timestep, apparently increasing the $\mathrm{CF}$ of the shallow cumulus regime.

Using the Hybrid Single Particle Lagrangian Integrated Trajectory Model (HYSPLIT) (Draxler and Hess, 1998) with a starting altitude of $1000 \mathrm{~m}$, we include the effect of advection on the observed changes in CF for the shallow cumulus regime. We use NCEP reanalysis data to determine trajectories from the centre of each $1^{\circ}$ by $1^{\circ}$ degree box. If this trajectory ends in a different box after $3 \mathrm{~h}$, data from that box is used to provide the end of timestep CF. We cover the period July-August-September for 2003-2011.

Comparing $d(\mathrm{CF})$ from the cases both with and without accounting for advection, we find the difference between them is generally much smaller than the magnitude of $d(\mathrm{CF})$ (Fig. 7). Taking into account advection does result in an increased $d(\mathrm{CF})$ over the north tropical Atlantic, as well as the east coast of South America. There is also a small increase over the Arabian Sea. In some cases neglecting advection reduces the observed $d(\mathrm{CF})$. In general the effect of advection 

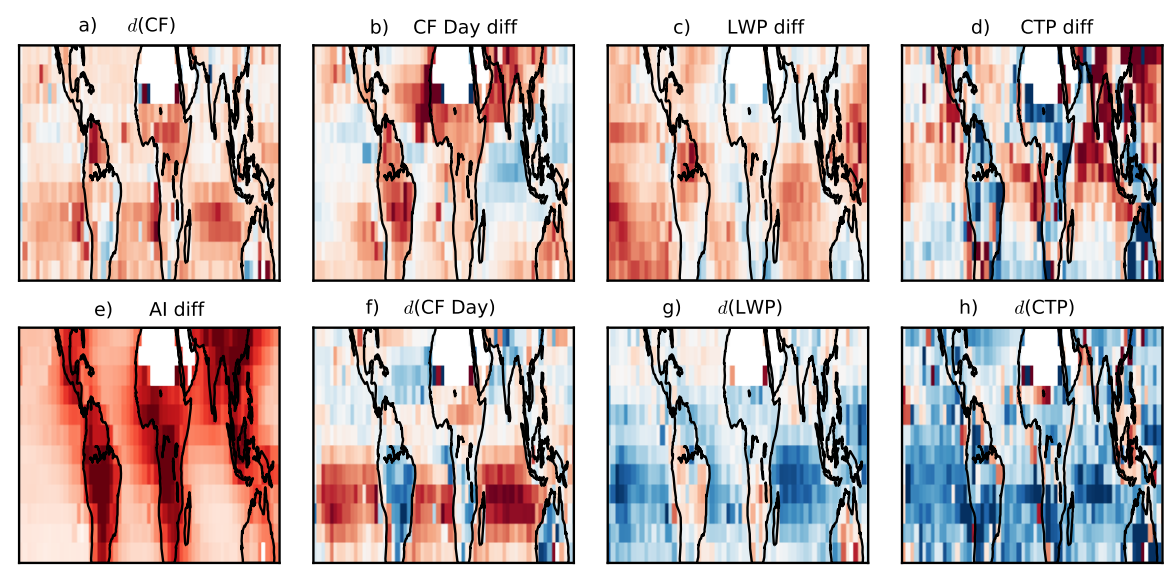

f) $d$ (CF Day)
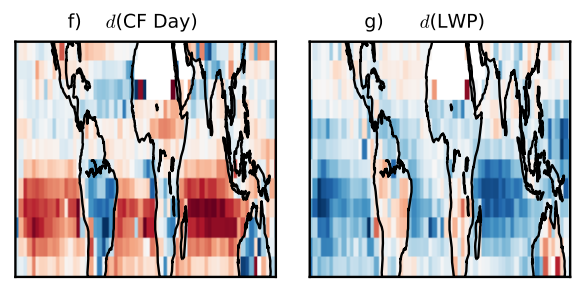

h) $d($ CTP $)$
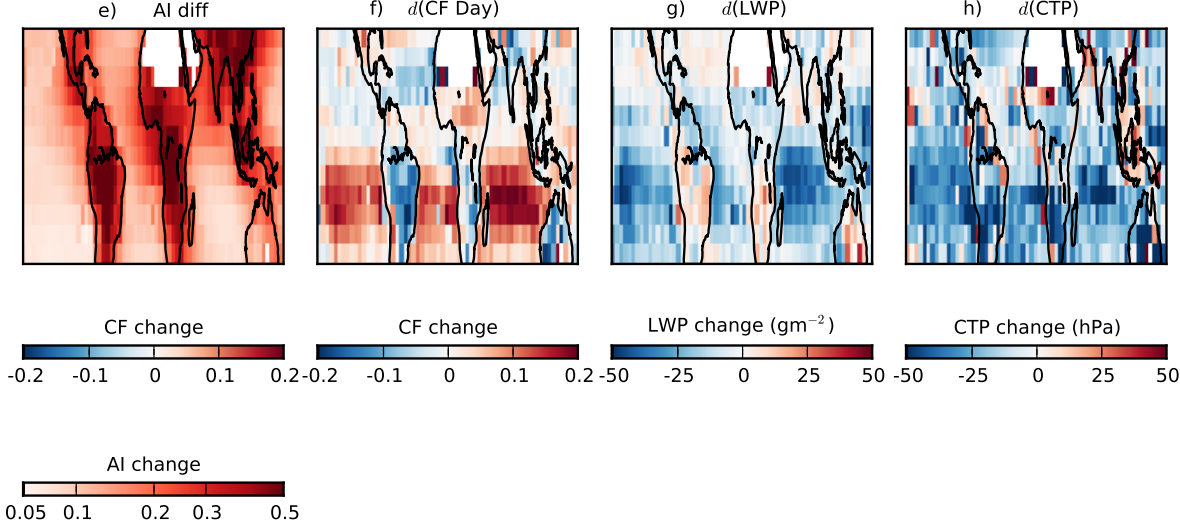

Fig. 5. The difference in end of timestep CF and AI between the low and high AI populations (a) and the difference in AI between the highest and lowest AI quartiles (e) for the shallow cumulus regime. The difference in CF Day (MODIS cloud mask), Liquid Water Path - Liquid clouds and Cloud Top Pressure at the start of the timestep (b-d), and the difference in the evolution of these quantities over the timestep (f-h). These plots all use MODIS Aqua and Terra data from 2003-2011, between $30^{\circ} \mathrm{N}$ and $30^{\circ} \mathrm{S}$.

is much smaller than the observed effect, justifying our assumption that the effects of advection can be neglected.

\subsection{Role of the retrieval product}

To investigate the possibility that the particular retrieval we are using could be generating our results, we also repeat them using data from the International Satellite Cloud Climatology Project (ISCCP) (Rossow and Schiffer, 1999). In the tropics, ISCCP uses mainly geostationary satellites, allowing several views of the same region each day. This also minimises effects from instrument variation over the day and allows investigation of the region around $180^{\circ} \mathrm{W}$ as there is no uncertainty in the timing of the retrievals. The cloud regimes used are from Williams and Webb (2009), which restricts the analysis in this section to $20^{\circ} \mathrm{N}-20^{\circ} \mathrm{S}$ as the regimes are not defined outside of this region. These are similar regimes to the ones used in this work, although there is not an exact correspondence due to differences between the instruments, retrievals and regimes determined by the clustering processes. We also use the GlobAerosol (Thomas et al., 2013) AOD retrieval from the AATSR instrument on the Envisat satellite. This is similar to Terra MODIS in that it is sun-synchronous and has an overpass time of approximately 1000 LST. It has a smaller swath, meaning that it only covers that entire tropics approximately once every three days. All of the data in this section is regridded to a common resolution of $2.5^{\circ}$ by $2.5^{\circ}$.
We find similar results (Figs. 8, 9) to those shown with MODIS data (Figs. 2, 3). With the AATSR AOD data, there is an increase in the strength of the convective pathway over land, which is also seen to a lesser extent over ocean. There is also a strong increase in the stratocumulus pathway over ocean, similar to the changes seen when using MODIS cloud and AI retrievals. When using MACC AOD, we find that the increase in the convective pathway over land is not a prominent as when using AATSR AOD, similar to when using MODIS cloud retrievals. This provides further evidence that our observed results are not due to the details or resolution of the cloud properties or aerosol retrievals.

\subsection{Relationship to long term effects}

The developmental studies presented here can only assess the possible effect of aerosol on cloud fraction over the period between the two cloud retrievals, approximately $3 \mathrm{~h}$ in this case. "Snapshot" studies, where the aerosol and cloud properties are retrieved at the same time, have the advantage that they represent the total time-integrated effect of aerosol on CF. However, we can use developmental studies to estimate the extent that a snapshot AI-CF correlation overestimates the influence of $\mathrm{AI}$ on $\mathrm{CF}$.

We make use of two AI retrievals, one AI retrieval with $\mathrm{CF}$ "effects" on AI (such as aerosol humidification and cloud contamination) included (similar to a "snapshot" study, Fig. 10c), and one where they are accounted for in the same way as the developmental studies in this work (Fig. 10b). We 

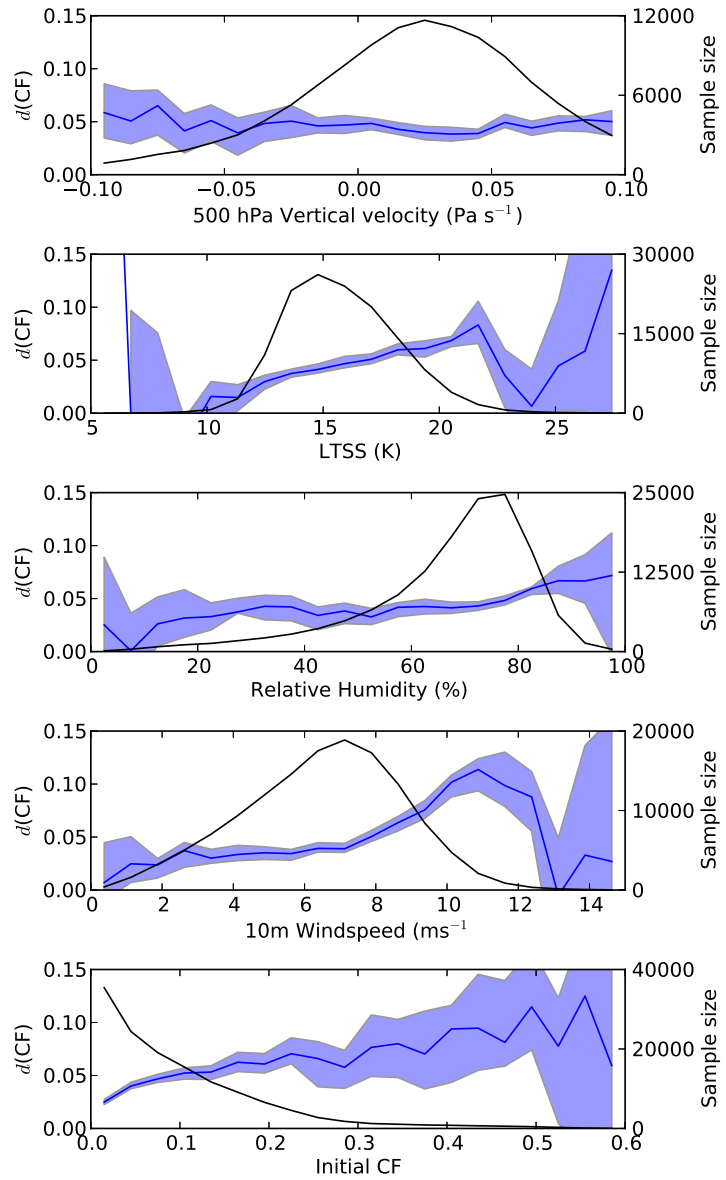

Fig. 6. The dependence of $d(\mathrm{CF})$ (blue) on initial meteorological parameters for the oceanic shallow cumulus regime. The distribution of points as a function of meteorological parameter is also shown by the solid black line. This plot is composed from MODIS data at all the oceanic shallow cumulus points over the years 2003-2011.

can then compare $d(\mathrm{CF})$ for each of these retrievals to examine how CF 'effects' on the retrieved AI affect observed AI-CF correlations.

We assume that the retrieved $\mathrm{AI}\left(\mathrm{AI}_{\text {retrieved }}\right)$ is composed of two parts, a part dependent on the actual $\mathrm{AI}\left(\mathrm{AI}_{\text {real }}\right)$ and a part dependent on some function of the $\mathrm{CF}(f(\mathrm{CF}))$ (Eq. 2). The developmental studies we have used so far have the same CF distribution for both the high and low AI populations and so the same CF contribution to the retrieved AI. This means we are sure that the high AI population has a high $\mathrm{AI}_{\text {real }}$, not just a higher CF. We define the $d(\mathrm{CF})$ calculated in the developmental studies as $d_{\text {real }}(\mathrm{CF})$ (Fig. 10b).

$\mathrm{AI}_{\text {retrieved }}=f(\mathrm{CF}) \times \mathrm{AI}_{\text {real }}$

Due to the method we use to account for the $\mathrm{CF}$ effects at the start of the timestep, we cannot use the same instrument at the same time to get an $\mathrm{AI}$ retrieval that includes $\mathrm{CF}$ effects for the same sample of clouds. However, at the end of the timestep, there is a second AI retrieval using Aqua MODIS.
We can make use of this retrieval as a "contaminated" AI retrieval, as it includes the $\mathrm{CF}$ dependent part. We refer to this $\mathrm{AI}$ retrieval as $\mathrm{AI}_{\text {retrieved }}$, and the corresponding $d(\mathrm{CF})$ as $d_{\text {retrieved }}(\mathrm{CF})$ (Fig. 10c). Due to the included CF effects, $d_{\text {retrieved }}(\mathrm{CF})$ is analogous to a "snapshot" study.

Assuming that $\mathrm{AI}_{\text {real }}$ is constant across the timestep, we can then compare $d(\mathrm{CF})$ calculated using an $\mathrm{AI}$ retrieval that has $\mathrm{CF}$ effects accounted for (as in the studies of regime transitions), and one that does not account for CF effects on the AI retrieval (as in "snapshot" studies). Comparing these for a single group of clouds shows the amount the AI-CF relationship is overestimated by studies using a "snapshot" of the $\mathrm{AI}$ and $\mathrm{CF}$ properties.

It is important to note that the effects of $\mathrm{CF}$ on $\mathrm{AI}$ are not necessarily due to cloud contamination of the AI retrieval. Some studies of the MODIS aerosol retrieval have suggested that the residual cloud contamination effect is small (Kaufman et al., 2005), while others suggest that it plays a larger role (Zhang et al., 2005). Quaas et al. (2010) suggested that the largest contributors to the AI-CF relationship are retrieval errors and humidification of aerosols. The effect of aerosols on CF is comparatively small in the GCM used in their study, and may still be overestimated (Quaas et al., 2009). As the effect of $\mathrm{AI}$ on $\mathrm{CF}$ is a small fraction of the total AI-CF correlation, we are justified in removing the link between $\mathrm{AI}$ and $\mathrm{CF}$ at the start of the timestep.

Table 2 shows the different values of $d(\mathrm{CF})$ over the tropics. As expected, $d_{\text {retrieved }}(\mathrm{CF})$ is larger than $d_{\text {real }}(\mathrm{CF})$ in all the regimes, over both land and ocean, in some cases by a significant margin. This shows that a snapshot AI-CF correlation will overestimate the magnitude of the possible AI effect on cloud fraction by at least a factor of two (Column $d_{\text {real }}(\mathrm{CF})$ Terra $/ d_{\text {retrieved }}(\mathrm{CF})$ in Table 2). This overestimation is slightly larger over land than over ocean, possibly due to the difficulty in retrieving aerosol over land.

We have assumed that $\mathrm{AI}_{\text {real }}$ is constant across the timestep, considering variations in $\mathrm{AI}_{\text {retrieved }}$ as due only to variations in $\mathrm{CF}$ (or related factors). An assumption of constant aerosol is reasonable in many cases, especially far from primary sources (Smirnov et al., 2002; Cachorro et al., 2004), but it will not be true in precipitating scenes, where aerosol will be removed from the atmosphere by wet scavenging. Whilst aerosol emissions would also vary $\mathrm{AI}_{\text {real }}$ over the $3 \mathrm{~h}$ timestep, emissions processes are not expected to be as regime dependent as wet scavenging.

We can get an estimate of the size of the wet scavenging effect by comparing $d_{\text {real }}(\mathrm{CF})$ calculated separately for both Aqua and Terra MODIS. If higher rainrates are correlated with high $\mathrm{CF}$, wet scavenging would be expected to reduce the difference in $\mathrm{AI}_{\text {real }}$ between the high and low AI populations for Aqua compared to Terra. This would result in a lower $d_{\text {real }}(\mathrm{CF})$ when calculated using Aqua MODIS AI compared to Terra.

We find this expected reduction, with $-d_{\text {real }}(\mathrm{CF})$ Aqua less than $d_{\text {real }}(\mathrm{CF})$ Terra (Table 2). The difference is larger in 


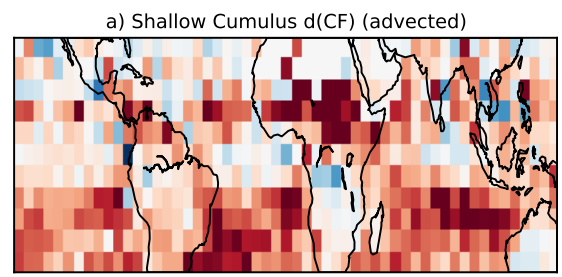

b) Shallow Cumulus d(CF) (not advected)

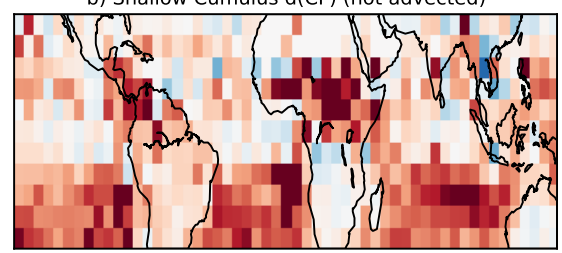

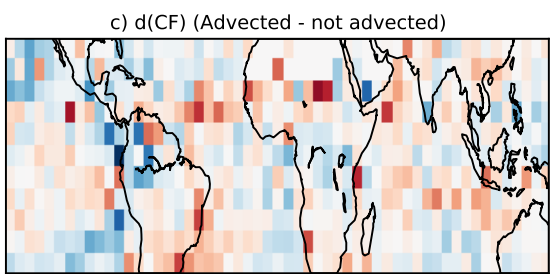

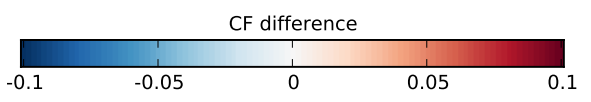

Fig. 7. The difference in the CF at the end of the timestep between the high AI and low AI populations $(d(\mathrm{CF}))$. This figure shows the difference when advection is taken into account using HYSPLIT (a), when the effects of advection are neglected (b) and the difference between them (c).

regimes that have a larger precipitation rate (Table 1), especially over land, providing further evidence that this change is the result of wet scavenging. The negative sign allows for a better comparison with $d_{\text {real }}(\mathrm{CF})$ Terra, as $d_{\text {real }}(\mathrm{CF})$ Aqua is determined using an $\mathrm{AI}$ retrieval at the end of the timestep, and so $d(\mathrm{CF})$ Aqua is determined backwards in time.

We cannot calculate the exact effect of wet scavenging, as we cannot calculate $d_{\text {real }}(\mathrm{CF})$ Aqua and $d_{\text {real }}(\mathrm{CF})$ Terra from a single group of clouds. Calculating $d_{\text {real }}(\mathrm{CF})$ Aqua requires setting $d_{\text {real }}(\mathrm{CF})$ Terra to zero (and vice-versa). Using separate populations of clouds (as we have done here) can only give an indication of the size of the wet scavenging effect.

The difference between $d_{\text {retrieved }}(\mathrm{CF})$ and $d_{\text {real }}(\mathrm{CF})$ shows the extent of the overestimation the AI-CF relationship when not accounting for the $\mathrm{CF}$ dependent part of the AI retrieval. This links our results from studying the regime transition frequencies to previous "snapshot" correlation studies.

\section{Correlation or causation}

When considering aerosol effects, it is important to consider possible interactions between the cloud and aerosol properties that could lead to the observed correlation, especially ones that are not due to aerosol effects. The strong correlation between AI and CF may lead to other correlations appearing, such as a CF reduction with increasing AI over the timestep, that are not the result of aerosol effects.

To account for the strong AI-CF relationship, we remove it at the start of the timestep, accounting for meteorological effects on the AI retrieval which are a function of CF (Sect. 2.2). The same process that we use for CF at the start of the timestep is also used for other meteorological variables that have been suggested to generate correlations between aerosol and cloud properties (Fig. 1). By investigating the transitions between the regimes over the timestep, we are able to determine if the AI-CF relationship returns, and to what extent. Even after these steps are taken to remove meteorological factors and possible biases from satellite retrieval errors, we still see a positive $d(\mathrm{CF})$ (an increase in CF in with increasing AI) at the end of the timestep (Fig. 5). This positive $d(\mathrm{CF})$, along with changes in other cloud properties generates transitions which are consistent with an aerosol effect on CF in stratiform clouds over ocean and the aerosol invigoration hypothesis in convective clouds over land (Fig. 3).

An important issue to note here is the different effects that meteorological covariations can have on correlations between aerosol and cloud properties. We can separate these effects based on how they interact with the AI retrieval. Type one meteorological effects modify the aerosol properties so as to change the retrieved AI without changing the number of CCN, and may also modify cloud properties. These type one effects include cloud contamination of the retrieval and aerosol humidification, although they may act as type two effects in certain situations. Given how these are thought to be major contributors to the AI-CF relationship, by accounting for the AI-CF relationship at the start of the timestep, we suggest that we have reduced the impact of these type one effects.

Type two meteorological covariations are much harder to account for. These effects modify cloud properties and the CCN number simultaneously, and so would not be accounted for even with a perfect $\mathrm{CCN}$ retrieval. They may occur globally, such as increased windspeed modifying sea salt fluxes (Woodcock, 1953) together with surface heat fluxes resulting in changes cloud properties (Nuijens and Stevens, 2012). More local effects may also play a role, such as Saharan dust outbreaks across the North Atlantic being accompanied by warm dry air (Carlson and Prospero, 1972), influencing cloud properties. Ensuring that the high and low AI populations have the same distribution of certain meteorological parameters should act to reduce these type two errors, but 

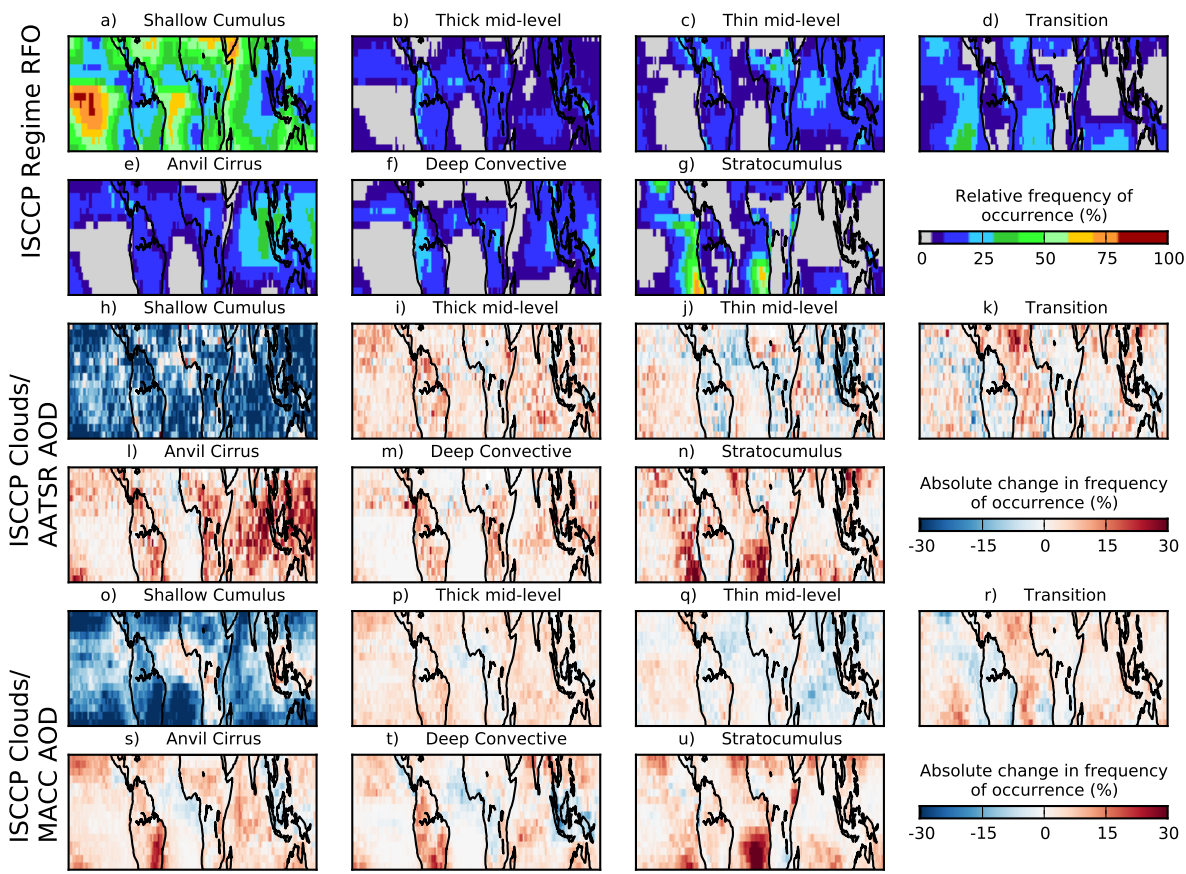

Fig. 8. (a) Relative frequency of occurrence (RFO) of each of the cloud regimes from ISCCP (Williams and Webb, 2009) over the period 2003-2007. The RFO is defined such that the sum of the RFOs for all of the regimes is $100 \%$. (b) shows the difference in frequency of occurrence of the regimes between the lowest and the highest MODIS AI quartiles. (c) as (b) but using MACC AOD instead of MODIS AI as the aerosol product.

Table 2. Difference in cloud fraction between high and low AI populations at the end of the timestep (Eq. 1). $d_{\text {real }}(\mathrm{CF})$ Terra uses an AI retrieval from the start of the timestep to determine a non-cloud contaminated AI, whereas $d_{\text {retrieved }}(\mathrm{CF})$ uses a contaminated retrieval performed at the end of the timestep. Both $d_{\text {real }}(\mathrm{CF})$ Terra and $d_{\text {retrieved }}(\mathrm{CF})$ use the same population of clouds. $-d_{\text {real }}(\mathrm{CF})$ Aqua is determined using an AI retrieval at the end of the timestep, and uses a different population of clouds, so it is not exactly comparable. It is presented as a negative due to the AI being retrieved at the end of the timestep, and so $d_{\text {real }}(\mathrm{CF})$ Aqua is determined "backwards" in time compared to the other measurements of $d(\mathrm{CF})$.

\begin{tabular}{lrrrr}
\hline Regime & $d_{\text {real }}(\mathrm{CF})$ Terra & $d_{\text {retrieved }}(\mathrm{CF})$ & $-d_{\text {real }}(\mathrm{CF})$ Aqua & $d_{\text {real }}(\mathrm{CF})$ Terra $/ d_{\text {retrieved }}(\mathrm{CF})$ \\
\hline Land & & & & \\
\hline Shallow Cumulus & 2.9 & 7.1 & 1.2 & 0.4 \\
Thick Mid Level & 6.1 & 12.5 & -4.4 & 0.5 \\
Thin Mid Level & 6.2 & 12.7 & -2.8 & 0.5 \\
Transitions & 2.6 & 7.4 & 3.3 & 0.4 \\
Anvil Cirrus & 4.0 & 9.4 & 1.7 & 0.4 \\
Deep Convective & - & - & -7.8 & - \\
Stratocumulus & 4.1 & 9.2 & 0.9 & 0.4 \\
\hline Ocean & & & & \\
\hline Shallow Cumulus & 3.9 & 7.1 & 1.1 & 0.6 \\
Thick Mid Level & 1.6 & 11.0 & 2.8 & 0.1 \\
Thin Mid Level & 5.2 & 10.7 & 4.3 & 0.5 \\
Transitions & 5.7 & 10.9 & 1.2 & 0.5 \\
Anvil Cirrus & 5.7 & 10.5 & 4.3 & - \\
Deep Convective & - & - & -6.3 & 0.4 \\
Stratocumulus & 4.6 & 10.4 & 3.7 & \\
\hline
\end{tabular}




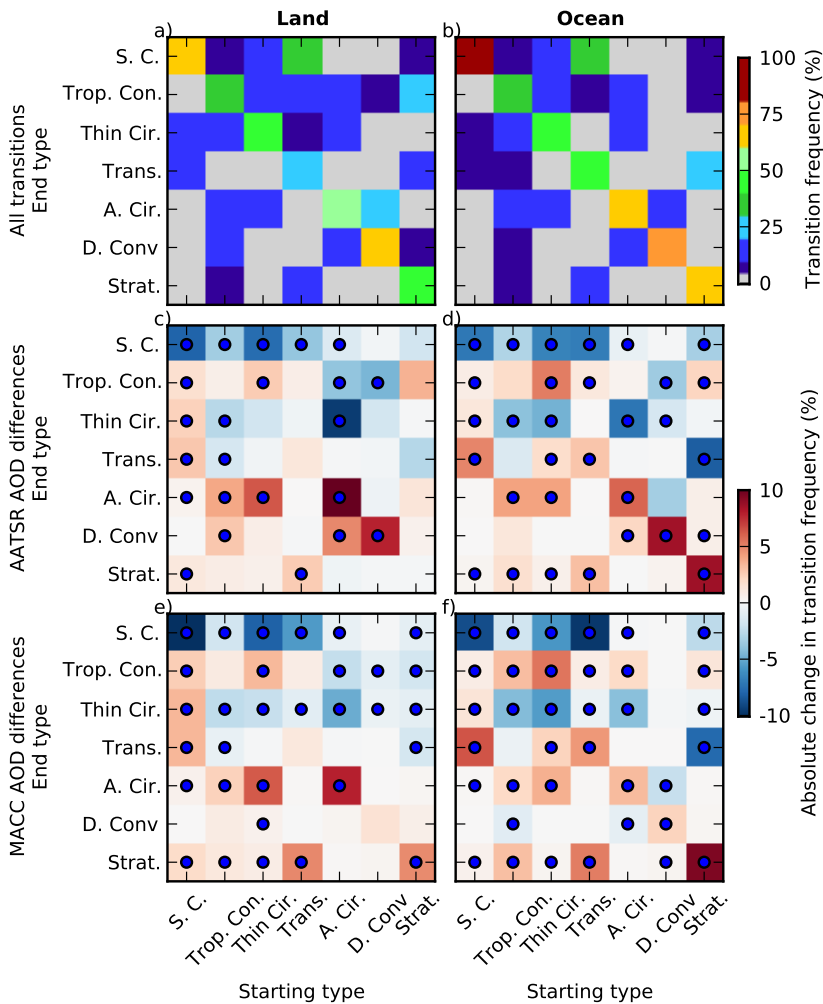

Fig. 9. Regime transition histogram showing the conditional probability of a given transitions between regimes over (a) land and (b) ocean during the $3 \mathrm{~h}$ afternoon period being observed, given each starting regime. As such, each column sums to $100 \%$. This plot covers regime transitions for the tropical region $\left(20^{\circ} \mathrm{N}-20^{\circ} \mathrm{S}\right)$. The difference in the histograms between the highest and lowest GlobAerosol AATSR quartile days over (c) land and (d) ocean, and using MACC AOD over (e) land and (f) ocean. Positive values indicate an increase in the frequency of the transition with increasing AI. Note the nonlinear colourbar in (a) and (b). The dots indicate statistical significance.

without a control experiment, they cannot be removed completely.

There is some evidence that the observed changes in transitions frequencies (Fig. 3) may not be due to an aerosol effect. $d(\mathrm{CF})$ is remarkably similar between regimes $\left(d_{\text {real }}(\mathrm{CF})\right.$ column in Table 2) and in the shallow cumulus regime it shows a much stronger link to LTSS (Fig. 6) than to the magnitude of change in AI (Fig. 5e). This is emphasised by the lower value of $d(\mathrm{CF})$ in the Northern Hemisphere, where a larger AI variance (Fig. 5e) might be expected to produce a larger $d(\mathrm{CF})$.

This hemispheric discrepancy over ocean might be explained by the nonlinearity of proposed aerosol effects resulting in a stronger interaction in cleaner regions. Over land, where the aerosol perturbation is larger, strong responses to aerosol perturbations are observed, indicating that this nonlinearity is perhaps not the main factor. The differing nature of the clouds in the different hemispheres (Wood et al., 2002)

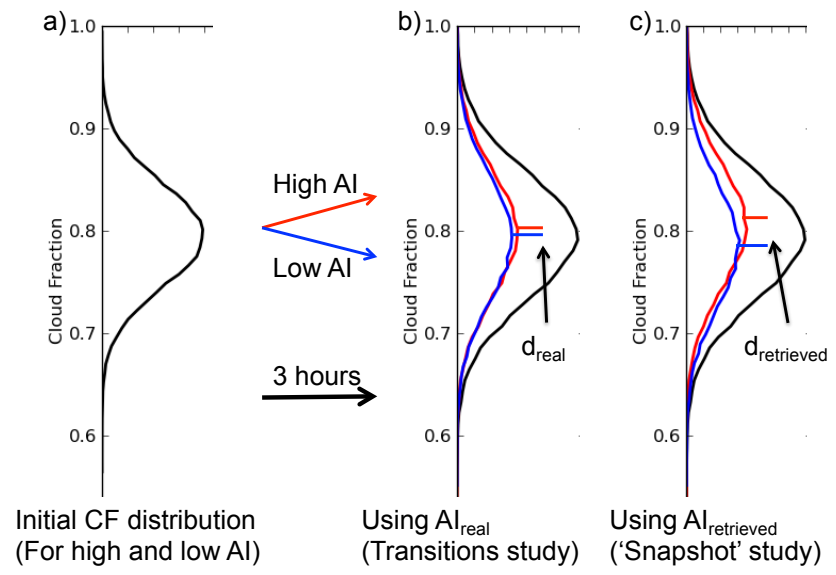

Fig. 10. Schematic demonstrating how the time of the aerosol retrieval can affect $d(\mathrm{CF})$. At the start of the timestep (a), both the high and low AI populations have the same CF distribution. (b) Despite starting with the same $\mathrm{CF}$, these populations evolve differently, generating $d_{\text {real }}(\mathrm{CF})$ at the end of the timestep. (c) Using the AI retrieval from the end of the timestep $\left(\mathrm{AI}_{\text {retrieved }}\right)$ gives a larger $\mathrm{CF}$ difference $d_{\text {retrieved }}(\mathrm{CF})$, due to aerosol humidification and cloud contamination, which increase with $\mathrm{CF}$.

probably plays an important role in determining the magnitude of the response to aerosol perturbations. The dependence of $d(\mathrm{CF})$ on meteorological factors would support this conclusion.

The nature of the re-analysis data used at the start of the timestep to account for meteorological covariations also introduces an uncertainty into our results. If the re-analysis was a perfect representation of the atmosphere, we would be able to use it to sample our results in such a way as to remove the influence of meteorological covariation. The imperfect representation of the atmosphere, coupled with our inability to sample every possible meteorological variable, suggests that our results provide the upper limit to an aerosol effect, as a better accounting for meteorological covariations might be expected to reduce any apparent aerosol effect on cloud properties.

\section{Conclusions}

In this study we have demonstrated a way to investigate aerosol-cloud interactions whilst accounting for the influences of CF and meteorological properties on the aerosol retrieval. This is of particular importance, as hypothesised aerosol effects that modify the CF in some manner cannot easily be separated from CF-related errors in the aerosol retrieval. Investigating the transitions between cloud regimes also allows us to directly view cloud development in different AI environments.

To do this, we make use of a regime based method, objectively splitting our data into separate cloud regimes based on 
k-means clustering of the MODIS histograms. This allows the study of the change in relative frequency of occurrence (RFO) of different cloud regimes with changing AI. By making use of the two time-separated MODIS retrievals, we also investigate the frequency of transitions between the regimes in high and low AI environments.

To ensure the transitions between regimes are not due to the strong AI-CF relationship, we make sure the CF distributions within each regime are the same for the high and low AI populations at the start of the timestep. By accounting for variations in $\mathrm{CF}$ with $\mathrm{AI}$, we are able to reduce meteorological errors due to the AI-CF correlation. The same method is also applied to other meteorological variables thought to have effects on correlations between aerosol and cloud properties, such as $10 \mathrm{~m}$ windspeed and low troposphere static stability. Accounting for $\mathrm{CF}$ influences on the $\mathrm{AI}$ retrieval gives us more confidence that it reflects the actual CCN. By ensuring similar meteorological conditions, we reduce the possibility that the observed results are due to differences in the meteorological environment.

We find that with increasing AI, the RFO of both stratiform cloud types and convective cloud types increases at the expense of the shallow cumulus regime. These results would be consistent with both with an aerosol influence on the transition between open and closed cell stratocumulus clouds and the aerosol invigoration hypothesis (Fig. 2).

The changes in regime RFOs are probably the result of the strong AI-CF relationship, and so could be considered as primarily the result of meteorological covariation (Quaas et al., 2010; Grandey et al., 2013). We also find increases in the probability of transitions to higher $\mathrm{CF}$ regimes with increased AI, as well as changes in regime transition frequencies consistent with the aerosol invigoration hypothesis (Fig. 3). These are less likely to be the result of the same meteorological covariation, as we have accounted for the relationship between $\mathrm{CF}$ and AI. With increasing AI we also find an increase in the persistence of marine stratiform types over ocean, contrary to some previous studies, which showed an increase in the breakup rate with increasing AOD. The increase in persistence is consistent with an aerosol influence on the open-closed cell transition in marine stratocumulus reducing the rate of dissipation of stratocumulus clouds. Similar changes in regime transition frequency are also found when using the ISCCP cloud product and the AATSR GlobAerosol AOD retrieval, indicating that this effect is not dependent on a single satellite product/retrieval (Fig. 9).

As AI cannot be retrieved in cloud covered scenes, we use the ECMWF MACC AOD product to investigate possible sampling errors. It suggests that the results in stratiform regions are unlikely to be significantly influenced by sampling errors. However, the reduced transition frequency into the deep convective regime found when using MACC AOD compared to MODIS AI suggests that the high precipitation rate and corresponding increased wet scavenging in the high
CF regimes may be important in determining any links between AI and convective cloud development (Fig. 3e, f).

To compare the magnitude of our results looking at cloud regime development with previous "snapshot" studies, we investigated the change in regime $\mathrm{CF}$ over the timestep using AI retrieved both at the start and the end of the timestep. This gives us one AI retrieval where CF influences are accounted for, and one where they are not, allowing an estimate of the effect of not accounting for the AI-CF relationship. We find that a simple AI-CF regression overestimates the link between $\mathrm{CF}$ and $\mathrm{AI}$ by at least a factor of two, although the exact amount is uncertain due to wet scavenging processes and uncertainty in the development of the cloud regime properties (Table 2).

The increases in transitions between regimes with increasing AI (Fig. 3), are consistent with previously hypothesised effects of aerosols on cloud development, even after accounting for the influence of $\mathrm{CF}$ and meteorological parameters at the time of the AI retrieval. Whilst this study does not rule out meteorological covariation, it does reduce the upper limit on the strength of an aerosol effect on CF by at least a factor of two (Table 2). This illustrates the importance accounting for $\mathrm{CF}$ and meteorological influences on aerosol retrievals.

The study demonstrates the powerful possibilities of studying cloud development for controlling for meteorological effects when investigating aerosol-cloud interactions. Further work is necessary to understand the relationship between development methods and "snapshot" studies so that the advantages of each method can be leveraged to better understand aerosol effects on cloud processes.

Acknowledgements. The MODIS data are from the NASA Goddard Space Flight Center and the ISCCP data are from the NASA Langley Atmospheric Research Center. This work was supported by a UK Natural Environment Research Council (NERC) DPhil studentship and funding from the European Research Council under the European Union's Seventh Framework Programme (FP7/2007-2013)/ERC grant agreement no. FP7-280025. EG is grateful for the the insights and suggestions of B. Stevens and L. Nuijens (Max Planck Institute for Meteorology) and for the hospitality of the International Max Planck Research School at the Max Planck institute for Meteorology.

Edited by: Y. Cheng

\section{References}

Albrecht, B.: Aerosols, Cloud Microphysics, and Fractional Cloudiness, Science, 245, 1227, 1989.

Anderberg, M.: Cluster Analysis for Applications, Elsevier, New York, 1973.

Andreas, E. L.: A new sea spray generation function for wind speeds up to $32 \mathrm{~ms}^{-1}$, J. Phys. Oceanogr., 28, 2175-2184, doi:10.1175/1520-0485(1998)028<2175:ANSSGF>2.0.CO;2, 1998. 
Cachorro, V., Pomero, P., Toledano, C., Cuevas, E., and de Frutos, A.: The fictitious diurnal cycle of aerosol optical depth: A new approach for 'in situ' calibration and correction of AOD data series, Geophys. Res. Lett., 31, L12106, doi:10.1029/2004GL019651, 2004.

Carlson, T. N. and Prospero, J. M.: The large-scale movement of Saharan air outbreaks over the Northern Equatorial Atlantic, J. Appl. Meteorol., 11, 283-297, 1972.

Chen, S. S. and Houze, R. A.: Diurnal variation and lifecycle of deep convective systems over the tropical pacific warm pool, Q. J. Roy Meteor. Soc., 123, 357-388, doi:10.1002/qj.49712353806, 1997.

Dee, D. P., Uppala, S. M., Simmons, A. J., Berrisford, P., Poli, P., Kobayashi, S., Andrae, U., Balmaseda, M. A., Balsamo, G., Bauer, P., Bechtold, P., Beljaars, A. C. M., van de Berg, L., Bidlot, J., Bormann, N., Delsol, C., Dragani, R., Fuentes, M., Geer, A. J., Haimberger, L., Healy, S. B., Hersbach, H., Hólm, E. V., Isaksen, L., Kållberg, P., Köhler, M., Matricardi, M., McNally, A. P., Monge-Sanz, B. M., Morcrette, J.-J., Park, B.-K., Peubey, C., de Rosnay, P., Tavolato, C., Thépaut, J.-N., and Vitart, F.: The ERA-Interim reanalysis: configuration and performance of the data assimilation system, Q. J. Roy. Meteor. Soc., 137, 553-597, doi:10.1002/qj.828, 2011.

Draxler, R. and Hess, G.: An overview of the HYSPLIT_4 modeling system of trajectories, dispersion, and deposition, Aust. Meteorol. Mag., 47, 295-308, 1998.

Efron, B.: Bootstrap methods: Another look at the jackknife, Ann. Stat., 7, 1-26, 1979.

Engstrom, A. and Ekman, A. M.: Impact of meteorological factors on the correlation between aerosol optical depth and cloud fraction, Geophys. Res. Lett., 37, L18814, doi:10.1029/2010GL044361, 2010.

Forster, P., Ramaswamy, V., Artaxo, P., Berntsen, T., Betts, R., Fahey, D., Haywood, J., Lean, J., Lowe, D., Myhre, G., Nganga, J., Prinn, R., Raga, G., Schulz, M., and Van Dorland, R.: Changes in Atmospheric Constituents and in Radiative Forcing, in: Climate Change 2007: The Physical Science Basis, Contribution of Working Group I to the Fourth Assessment Report of the Intergovernmental Panel on Climate Change, edited by: Solomon, S., Qin, D., Manning, M., Chen, Z., Marquis, M., Averyt, K. B., Tignor, M., and Miller, H., Chapter 2, Cambridge University Press, Cambridge, United Kingdom and New York, NY, USA, 2007.

Grandey, B. S. and Stier, P.: A critical look at spatial scale choices in satellite-based aerosol indirect effect studies, Atmos. Chem. Phys., 10, 11459-11470, doi:10.5194/acp-10-11459-2010, 2010.

Grandey, B. S., Stier, P., and Wagner, T. M.: Investigating relationships between aerosol optical depth and cloud fraction using satellite, aerosol reanalysis and general circulation model data, Atmos. Chem. Phys., 13, 3177-3184, doi:10.5194/acp-13-31772013, 2013.

Gryspeerdt, E. and Stier, P.: Regime-based analysis of aerosolcloud interactions, Geophys. Res. Lett., 39, L21802, doi:10.1029/2012GL053221, 2012.

Haywood, J. and Shine, K.: The effect of anthropogenic sulfate and soot aerosol on the clear sky planetary radiation budget, Geophys. Res. Lett., 22, 603-606, doi:10.1029/95GL00075, 1995.

Hubanks, P. A., King, M. D., Platnick, S. A., and Pincus, R. A.: MODIS Atmosphere L3 Gridded Product Algorithm Theoreti- cal Basis Document No. ATBD-MOD-30, Tech. rep., National Aeronautics and Space Administration, 2008.

Huffman, G. J., Adler, R. F., Bolvin, D. T., and Gu, G.: Improving the global precipitation record: GPCP Version 2.1, Geophys. Res. Lett., 36, 17808, doi:10.1029/2009GL040000, 2009.

Kaufman, Y., Koren, I., Remer, L., Rosenfeld, D., and Rudich, Y.: The effect of smoke, dust, and pollution aerosol on shallow cloud development over the Atlantic Ocean, P. Natl. Acad. Sci. USA, 102, 11207, doi:10.1073/pnas.0505191102, 2005.

Kientzler, C. F., Arons, A. B., Blanchard, D. C., and Woodcock, A. H.: Photographic Investigation of the Projection of Droplets by Bubbles Bursting at a Water Surface, Tellus, 6, 1-7, 1954.

Klein, S. and Hartmann, D.: The seasonal cycle of low stratiform clouds, J. Climate, 6, 1587-1606, doi:10.1175/15200442(1993)006<1587:TSCOLS>2.0.CO;2, 1993.

Koch, D. and Del Genio, A. D.: Black carbon semi-direct effects on cloud cover: review and synthesis, Atmos. Chem. Phys., 10, 7685-7696, doi:10.5194/acp-10-7685-2010, 2010.

Koren, I., Kaufman, Y., Rosenfeld, D., Remer, L., and Rudich, Y.: Aerosol invigoration and restructuring of Atlantic convective clouds, Geophys. Res. Lett., 32, L14828, doi:10.1029/2005GL023187, 2005.

Koren, I., Feingold, G., and Remer, L. A.: The invigoration of deep convective clouds over the Atlantic: aerosol effect, meteorology or retrieval artifact?, Atmos. Chem. Phys., 10, 8855-8872, doi:10.5194/acp-10-8855-2010, 2010a.

Koren, I., Remer, L. A., Altaratz, O., Martins, J. V., and Davidi, A.: Aerosol-induced changes of convective cloud anvils produce strong climate warming, Atmos. Chem. Phys., 10, 5001-5010, doi:10.5194/acp-10-5001-2010, 2010b.

Lee, D., Oreopoulos, L., Huffman, G. J., Rossow, W. B., and Kang, I.-S.: The Precipitation Characteristics of ISCCP Tropical Weather States, J. Climate, 26, 772-788, doi:10.1175/JCLI-D11-00718.1, 2013.

Levy, R. C., Remer, L. A., Kleidman, R. G., Mattoo, S., Ichoku, C., Kahn, R., and Eck, T. F.: Global evaluation of the Collection 5 MODIS dark-target aerosol products over land, Atmos. Chem. Phys., 10, 10399-10420, doi:10.5194/acp-10-10399-2010, 2010.

Machado, L. A. T., Laurent, H., and Lima, A. A.: Diurnal march of the convection observed during TRMM-WETAMC/LBA, J. Geophys. Res., 107, 8064, doi:10.1029/2001JD000338, 2002.

Matsui, T., Masunaga, H., Kreidenweis, S., Pielke, R., Tao, W.-K., Chin, M., and Kaufman, Y.: Satellite-based assessment of marine low cloud variability associated with aerosol, atmospheric stability, and the diurnal cycle, J. Geophys. Res., 111, D17204, doi:10.1029/2005JD006097, 2006.

Mauger, G. and Norris, J.: Meteorological bias in satellite estimates of aerosol-cloud relationships, Geophys. Res. Lett., 34, D16824, doi:10.1029/2007GL029952, 2007.

Mauger, G. and Norris, J.: Assessing the impact of meteorological history on subtropical cloud fraction, J. Climate, 23, 2926, doi:10.1175/2010JCLI3272.1, 2010.

Meskhidze, N., Remer, L. A., Platnick, S., Negrón Juárez, R., Lichtenberger, A. M., and Aiyyer, A. R.: Exploring the differences in cloud properties observed by the Terra and Aqua MODIS Sensors, Atmos. Chem. Phys., 9, 3461-3475, doi:10.5194/acp9-3461-2009, 2009.

Nakajima, T., Higurashi, A., Kawamoto, K., and Penner, J.: A possible correlation between satellite-derived cloud and aerosol 
microphysical parameters, Geophys. Res. Lett., 28, 1171-1174, doi:10.1029/2000GL012186, 2001.

Nuijens, L. and Stevens, B.: The influence of Wind Speed on Shallow Marine Convection, J. Atmos. Sci., 69, 168-184, doi:10.1175/JAS-D-11-02.1, 2012.

Pincus, R., Baker, M. B., and Bretherton, C. S.: What controls Stratocumulus Radiative Properties? Lagrangian Observations of Cloud Evolution, J. Atmos. Sci., 54, 2215-2236, doi:10.1175/1520-0469(1997)054<2215:WCSRPL>2.0.CP:;, 1997.

Platnick, S., King, M., Ackerman, S., Menzel, W., Baum, B., Riedi, J., and Frey, R.: The MODIS cloud products: algorithms and examples from Terra, IEEE T. Geosci. Remote, 41, 459-473, doi:10.1109/TGRS.2002.808301, 2003.

Quaas, J., Ming, Y., Menon, S., Takemura, T., Wang, M., Penner, J. E., Gettelman, A., Lohmann, U., Bellouin, N., Boucher, O., Sayer, A. M., Thomas, G. E., McComiskey, A., Feingold, G., Hoose, C., Kristjánsson, J. E., Liu, X., Balkanski, Y., Donner, L. J., Ginoux, P. A., Stier, P., Grandey, B., Feichter, J., Sednev, I., Bauer, S. E., Koch, D., Grainger, R. G., Kirkevåg, A., Iversen, T., Seland, Ø., Easter, R., Ghan, S. J., Rasch, P. J., Morrison, H., Lamarque, J.-F., Iacono, M. J., Kinne, S., and Schulz, M.: Aerosol indirect effects - general circulation model intercomparison and evaluation with satellite data, Atmos. Chem. Phys., 9, 8697-8717, doi:10.5194/acp-9-8697-2009, 2009.

Quaas, J., Stevens, B., Stier, P., and Lohmann, U.: Interpreting the cloud cover - aerosol optical depth relationship found in satellite data using a general circulation model, Atmos. Chem. Phys., 10, 6129-6135, doi:10.5194/acp-10-6129-2010, 2010.

Remer, L., Kaufman, Y., Tanré, D., Matto, S., Chu, D., Martins, J., Li, R.-R., Ichoku, C., Levy, R., Kleidman, R., Eck, T., Vermote, E., and Holben, B.: The MODIS aerosol algorithm, products, and validation, J. Atmos. Sci., 62, 947-973, doi:10.1175/JAS3385.1, 2005.

Rosenfeld, D., Kaufman, Y. J., and Koren, I.: Switching cloud cover and dynamical regimes from open to closed Benard cells in response to the suppression of precipitation by aerosols, Atmos. Chem. Phys., 6, 2503-2511, doi:10.5194/acp-6-2503-2006, 2006.

Rosenfeld, D., Lohmann, U., Raga, G., O’Dowd, C., Kulmala, M., Fuzzi, S., Reissell, A., and Andreae, M.: Flood or Drought: How Do Aerosols Affect Precipitation?, Science, 321, 1309-1313, doi:10.1126/science.1160606, 2008.

Rossow, W. and Schiffer, R.: Advances in Understanding Clouds from ISCCP., B. Am. Meteorol. Soc., 80, 2261, 1999.

Rossow, W. B., Tselioudis, G., Polak, A., and Jakob, C.: Tropical climate described as a distribution of weather states indicated by distinct mesoscale cloud property mixtures, Geophys. Res. Lett., 32, L21812, doi:10.1029/2005GL024584, 2005.

Sandu, I., Brenguier, J.-L., Geoffory, O., Thouron, O., and Masson, V.: Aerosol impacts on the diurnal cycle of marine stratocumulus, J. Atmos. Sci., 65, 2705-2718, doi:10.1175/2008JAS2451.1, 2008.

Sayer, A. M., Thomas, G. E., and Grainger, R. G.: A sea surface reflectance model for (A)ATSR, and application to aerosol retrievals, Atmos. Meas. Tech., 3, 813-838, doi:10.5194/amt-3813-2010, 2010a.

Sayer, A. M., Thomas, G. E., Palmer, P. I., and Grainger, R. G.: Some implications of sampling choices on comparisons between satellite and model aerosol optical depth fields, Atmos. Chem. Phys., 10, 10705-10716, doi:10.5194/acp-10-107052010, 2010b.

Seethala, C. and Horvath, A.: Global assessment of AMSR$\mathrm{E}$ and MODIS cloud liquid water path retrievals in warm oceanic clouds, J. Geophys Res., 115, D13202, doi:10.1029/2009JD012662, 2010.

Smirnov, A., Holben, B., Eck, T., Slutsker, I., Chatenet, B., and Pinker, R.: Diurnal variability of aerosol optical depth observed at AERONET sites, Geophys. Res. Lett., 29, 2115, doi:10.1029/2002GL016305, 2002.

Stevens, B. and Feingold, G.: Untangling aerosol effects on clouds and precipitation in a buffered system, Nature, 461, 607-613, doi:10.1038/nature08281, 2009.

Stevens, B., Ackerman, A. S., Albrecht, B. A., Brown, A. R., Chlond, A., Cuxart, J., Duynkerke, P. G., Lewellen, D. C., Macvean, M. K., Neggers, R. A. J., Sánchez, E., Siebesma, A. P., and Stevens, D. E.: Simulations of Trade Wind Cumuli under a Strong Inversion, J. Atmos. Sci., 58, 1870-1891, doi:10.1175/1520-0469(2001)058<1870:SOTWCU>2.0.CO;2, 2001.

Thomas, G. E., Chalmers, N., Harris, B., Grainger, R. G., and Highwood, E. J.: Regional and monthly and clear-sky aerosol direct radiative effect (and forcing) derived from the GlobAEROSOLAATSR satellite aerosol product, Atmos. Chem. Phys., 13, 393 410, doi:10.5194/acp-13-393-2013, 2013.

Twomey, S.: Pollution and the Planetary Albedo, Atmos. Environ., 8, 1251-1256, 1974.

Wen, G., Marshak, A., Cahalan, R., Remer, L., and Kleidman, R.: 3-D aerosol-cloud radiative interaction observed in collocated MODIS and ASTER images of cumulus cloud fields, J. Geophys. Res., 112, D13204, doi:10.1029/2006JD008267, 2007.

Williams, E., Rosenfeld, D., Madden, N., Gerlach, J., Gears, N., Atkinson, L., Dunnemann, N., Frostrom, G., Antonio, M., Biazon, B., Camargo, R., Franca, H., Gomes, A., Lima, M., Machado, R., Manhaes, S., Nachtigall, L., Piva, H., Quintiliano, W., Machado, L., Artaxo, P., Roberts, G., Renno, N., Blakeslee, R., Bailey, J., Boccippio, D., Betts, A., Wolff, D., Roy, B., Halverson, J., Rickenbach, T., Fuentes, J., and Avelino, E.: Contrasting convective regimes over the Amazon: Implications for cloud electrification, J. Geophys. Res., 107, 8082, doi:10.1029/2001JD000380, 2002.

Williams, K. and Webb, M.: A quantitative performance assessment of cloud regimes in climate models, Clim. Dynam., 33, 141-157, doi:10.1007/s00382-008-0443-1, 2009.

Wood, R.: Stratocumulus Clouds, Mon. Weather Rev., 140, 2373 2423, doi:10.1175/MWR-D-11-00121.1, 2012.

Wood, R., Bretherton, C. S., and Hartmann, D. L.: Diurnal cycle of liquid water path over the subtropical and tropical oceans, Geophys. Res. Lett., 29, 2092, doi:10.1029/2002GL015371, 2002.

Woodcock, A.: Salt nuclei in marine air as a function of altitude and wind force, J. Meteorol., 10, 362-371, 1953.

Xiong, X., Wu, A., and Cao, C.: On-orbit calibration and inter-comparison of Terra and Aqua MODIS surface temperature spectral bands, Int. J. Remote Sens., 29, 5347-5359, doi:10.1080/01431160802036300, 2008.

Yang, G.-Y. and Slingo, J.: The Diurnal Cycle in the Tropics, Mon. Weather Rev., 129, 784-801, 2001. 
Zhang, J., Reid, J., and Holben, B.: An analysis of potential cloud artifacts in MODIS over ocean aerosol optical thickness products, Geophys. Res. Lett., 32, L15803, doi:10.1029/2005GL023254, 2005.
Zuidema, P., Painemal, D., de Szoke, S., and Fairall, C.: Stratocumulus Cloud-Top Height Estimates and Their Climatic Implications, J. Climate, 22, 4652-4666, doi:10.1175/2009JCLI2708.1, 2009. 